\title{
Lycium barbarum Polysaccharides Protect against Trimethyltin Chloride-Induced Apoptosis via Sonic Hedgehog and PI3K/Akt Signaling Pathways in Mouse Neuro-2a Cells
}

\author{
Wanyun Zhao, Xiaoqi Pan, Tao Li, Changchun Zhang, and Nian Shi \\ Department of Health Toxicology, MOE Key Lab of Environment and Health, School of Public Health, \\ Tongji Medical College, Huazhong University of Science and Technology, Wuhan 430030, China
}

Correspondence should be addressed to Nian Shi; sniantjmu@163.com

Received 26 November 2015; Revised 19 February 2016; Accepted 10 March 2016

Academic Editor: Javier Egea

Copyright (c) 2016 Wanyun Zhao et al. This is an open access article distributed under the Creative Commons Attribution License, which permits unrestricted use, distribution, and reproduction in any medium, provided the original work is properly cited.

\begin{abstract}
Trimethyltin chloride (TMT) is a classic neurotoxicant that can cause severe neurodegenerative diseases. Some signaling pathways involving cell death play pivotal roles in the central nervous system. In this study, the role of Sonic Hedgehog (Shh) and PI3K/Akt pathways in TMT-induced apoptosis and protective effect of Lycium barbarum polysaccharides (LBP) on mouse neuro-2a (N2a) cells were investigated. Results showed that TMT treatment significantly enhanced apoptosis, upregulated proapoptotic Bax, downregulated antiapoptotic Bcl-2 expression, and increased caspase-3 activity in a dose-dependent manner in N2a cells. TMT induced oxidative stress in cells, performing reactive oxygen species (ROS) and malondialdehyde (MDA) excessive generation, and superoxide dismutase (SOD) activity reduction. TMT significantly decreased phosphorylated glycogen synthase kinase- $3 \beta$ (GSK$3 \beta$ ) and inhibited Shh and PI3K/Akt pathways. However, the addition of LBP upregulated GSK-3 $\beta$ phosphorylation, activated Shh and PI3K/Akt pathways, and eventually reduced apoptosis and oxidative stress caused by TMT. The interaction between Shh and PI3K/Akt pathways was clarified by specific PI3K inhibitor LY294002 or Shh inhibitor GDC-0449. Moreover, LY294002 and GDC0449 pretreatment both induced phosphorylated GSK-3 $\beta$ downregulation and significantly promoted apoptosis induced by TMT. These results suggest that LBP could reduce TMT-induced N2a cells apoptosis by regulating GSK-3 $\beta$ phosphorylation, Shh, and PI3K/Akt signaling pathways.
\end{abstract}

\section{Introduction}

Trimethyltin chloride (TMT), an organotin compound and extremely neurotoxic agent, is generated in plastic and agricultural industries, producing polyvinyl chloride, silicone products, and fungicides [1]. Accumulating evidences suggested that TMT could lead to neuronal degeneration in humans and rodents [2-4]. TMT administration induces Parkinson's disease (PD) like symptoms (seizures), behavioral alterations (hyperactivity, tail mutilation, and aggression), and Alzheimer's disease (AD) like symptom (memory loss and learning impairment) [5]. Several studies indicated that TMT-induced neuronal degeneration is mainly due to cell apoptosis, activation of caspase family members, neuroinflammation, and oxidative stress $[4,6,7]$. Our early research has shown that there is cross talk and a balance between
NF- $\kappa$ B and MAPKs which may be involved in TMT-induced apoptosis on SH-SY5Y cells [8]. Despite numerous biochemical and neurochemical studies on TMT, its underlying neurotoxicity mechanism remains unknown.

Glycogen synthase kinase-3 $\beta$ (GSK-3 $\beta$ ), GSK-3 isoform, is an important protein involved in signaling pathways, involving Notch, PI3K/Akt, Wnt, and Hedgehog. Overexpression of GSK-3 $\beta$ mRNA in neurons significantly promoted neuronal apoptosis [9]. Currently, GSK-3 $\beta$ is a new targeted treatment point in cancer [10]. Sonic Hedgehog (Shh), a mammalian member of the Hedgehog family, regulates the polarity of the central nervous system [11]. A recent study reported the interrelationship between Shh pathway and oxidative stress in vivo [12]. The activity of Shh signaling pathway in targeting gene expression is controlled by the Gli family (Glil, Gli2, and Gli3), which is primarily regulated by 
GSK-3 [10]. PI3K/Akt signaling pathway serves a prosurvival function in neurons exposed to oxidative stress and apoptosis induced by various stimuli. The activated Akt confers cell survival by phosphorylating its cytoplasmic targets, such as GSK-3 $\beta$, Bcl-2, Bax, and caspase-9 [13].

Fructus Lycii also called wolfberry is the dried mature fruit of Lycium barbarum. Fructus Lycii is a common traditional Chinese medicine used to protect the nervous system, improve immunity, regulate blood sugar, and protect the eyes $[14,15]$. Fructus Lycii not only functions as an antioxidant agent but also exhibits other pleiotropic effects through its active component, namely, Lycium barbarum polysaccharides (LBP) $[16,17]$. The polysaccharide exhibits neuroprotective effects on reducing cortical neuronal death in $\mathrm{AD}$ and is considered as a potential candidate for neurological disorders prevention [18]. Although several studies have reported the neuroprotective effect of LBP on neurodegenerative disease, the specific mechanism of the compound remains uncertain.

In this study, we evaluated whether TMT induced neuronal damage in N2a cells, in which GSK-3 $\beta$ expression and cross talk between Shh and PI3K/Akt pathways played crucial roles. Moreover, the beneficial effect of LBP on TMT-induced apoptosis in $\mathrm{N} 2$ a cells was investigated.

\section{Materials and Methods}

2.1. Reagents and Instruments. TMT (>98\% purity) was obtained from Tokyo Kasei Kogyo Co. (Tokyo, Japan). Dulbecco's modified Eagle's medium (DMEM) for cell culture was purchased from Hyclone. LBP (active ingredient > 31\%) was provided by Shanghai Kangzhou Fungi Extract Co. (Shanghai, China). Antibodies against GSK-3 $\beta$, p-GSK-3 $\beta$ (Ser9), Akt, p-Akt (Thr308), CyclinD1, C-Myc, GAPDH, and PI3K inhibitor LY294002 were acquired from Cell Signal Technology, Inc. (Beverly, MA). Antibodies against Glil and Shh were obtained from Abcam Inc. Antibodies against Bcl-2 and Bax were purchased from Santa Cruz Biotechnology Inc. (Santa Cruz, CA). Shh inhibitor GDC0449 was obtained from Selleckchem, Inc. Reactive oxygen species (ROS) and caspase- 3 activity assay kits were purchased from Beyotime Institute of Biotechnology (Shanghai, China). Malondialdehyde (MDA) and superoxide dismutase (SOD) kit were obtained from Nanjing Jiancheng Bioengineering Institute (Nanjing, China). PE-Annexin-V/7-AAD apoptosis detection kit was acquired from BD Pharmingen, Inc. (San Diego, CA). 3-(4,5-Dimethylthiazol-2-yl)-2,5diphenyltetrazolium bromide (MTT) and Hoechst33258 dye were provided by Sigma Co.

2.2. Cell Culture and Treatment. Mouse Neuro-2a (N2a) cells were purchased from Shanghai Institute for Biological Sciences, Chinese Academy of Cell Resource Center (Shanghai, China). Cells were maintained at $37^{\circ} \mathrm{C}$ in a humidified atmosphere of $95 \% \mathrm{O}_{2}$ and $5 \% \mathrm{CO}_{2}$ in DMEM supplemented with $10 \%$ fetal bovine serum (FBS), penicillin $(100 \mathrm{U} / \mathrm{mL})$, and streptomycin $(100 \mathrm{U} / \mathrm{mL})$. The culture medium was replaced every 2 days. Cells were collected and seeded in new culture bottles. After incubation for $24 \mathrm{~h}$, the medium was changed with serum-free medium containing different concentrations of TMT, LBP, and antagonists. TMT and LBP were dissolved in distilled water. The pharmacological inhibitors were dissolved in dimethyl sulfoxide (DMSO), and the final DMSO concentration in the medium was $0.1 \%$ to avoid any negative effects on cell survival. The cells were cotreated with LBP and TMT for $24 \mathrm{~h}$ or pretreated with LY294002 and GDC-0449 for 1 and $2 \mathrm{~h}$, respectively, before TMT exposure for $24 \mathrm{~h}$.

2.3. Cell Viability Assay. Cell viability was detected by MTT assays. Briefly, N2a cells were seeded in 96-well plates at a density of $10^{4}$ cells/well in DMEM (high glucose) containing $10 \%$ FBS. After seeding for $24 \mathrm{~h}$, the medium was removed and replaced with $200 \mu \mathrm{L}$ of fresh medium containing serial concentrations of TMT $(0.46875 \sim 120 \mu \mathrm{M}), \mathrm{LBP}(300 \mu \mathrm{g} / \mathrm{mL})$, or antagonists. After $24 \mathrm{~h}$ of incubation, the cells were treated with $20 \mu \mathrm{L}$ of fresh medium containing $0.5 \mathrm{mg} / \mathrm{mL}$ MTT and incubated at $37^{\circ} \mathrm{C}$ for $4 \mathrm{~h}$. The solution was removed, and about $150 \mu \mathrm{L}$ of DMSO was added to each well to dissolve the purple formazan crystals. Absorbance was determined at $490 \mathrm{~nm}$ by using a microplate reader. Results were expressed as the percentage of MTT reduction relative to the absorbance of control cells.

2.4. Flow Cytometric Analysis. Early stages of apoptosis were analyzed using a PE-Annexin-V/7-AAD apoptosis detection kit. After exposure to the test agents for $24 \mathrm{~h}$, cells were harvested, washed with PBS and binding buffer, and stained for $10 \mathrm{~min}$ with $\mathrm{PE}$ and 7-AAD (dissolved in the binding buffer provided by the manufacturer). The numbers of PEpositive/7-AAD-negative, PE-positive/7-AAD-positive, and PE-negative/7-AAD-positive cells and unlabeled cells were determined with a Becton-Dickinson FACS flow cytometer. Data were analyzed using Cell Quest software, and 10,000 events were assessed for each independent experiment. The numbers of 7-AAD-positive/PE-positive (necrotic cells, quadrant I), 7-AAD-positive/PE-negative (late apoptotic, quadrant II), AV-negative/PI-positive (early apoptotic, quadrant IV), and unlabeled (intact cells, quadrant III) cells were determined.

2.5. Immunocytofluorescence Staining Analysis. Cells were incubated on pretreated coverslips. After exposure to TMT $(1.875,3.75$, and $7.5 \mu \mathrm{M})$ and/or LBP $(300 \mu \mathrm{g} / \mathrm{mL})$ for $24 \mathrm{~h}$, the cells were fixed with $4 \%$ paraformaldehyde for $20 \mathrm{~min}$ at room temperature. The slides were incubated for $20 \mathrm{~min}$ in $0.3 \%$ Triton X-100 diluted with $0.1 \mathrm{M}$ PBS for permeabilization, rinsed three times in PBS, and blocked with normal goat serum for $20 \mathrm{~min}$ at room temperature. Rabbit antimouse $\mathrm{p}$-Akt and p-GSK-3 $\beta$ polyclonal antibodies $(1: 300$ and $1: 500)$ were used as primary antibodies. The slides were then incubated with primary antibodies at $4^{\circ} \mathrm{C}$ overnight and reacted with FITC-conjugated goat anti-rabbit IgG antibody $(1: 100)$ for $1 \mathrm{~h}$ at room temperature. DAPI dye was used for nuclear staining before washing, and the coverslips were covered on the slides with an antifade mounting medium. Images 
were captured and digitized under an inverted fluorescence microscope (IX71, Olympus, Japan).

\subsection{DNA Condensation and Nuclear Fragmentation.} Hoechst33258 fluorescent dye was used to determine DNA condensation and nuclear fragmentation of apoptotic cells. N2a cells were seeded in a six-well plate at a density of $5 \times 10^{4}$ cells/well. After treatment with or without TMT and LBP for $24 \mathrm{~h}$ at $37^{\circ} \mathrm{C}$, the cells were washed with PBS and fixed with $4 \%$ paraformaldehyde for $20 \mathrm{~min}$ at $4^{\circ} \mathrm{C}$. The fixed cells were washed with PBS and stained with $5 \mu \mathrm{g} / \mathrm{mL}$ Hoechst 33258 for $10 \mathrm{~min}$. After incubation, the cells were washed again with PBS. Images were obtained under an inverted fluorescence microscope (IX71, Olympus, Japan).

2.7. Detection of Intracellular ROS Accumulation. A fluorescence probe (DCFH-DA) was used to determine ROS in N2a cells. DCFH-DA was deacetylated in cells, where it could react with free radicals $\left(\mathrm{H}_{2} \mathrm{O}_{2}\right)$ and be converted into the fluorescent product DCF. N2a cells were incubated with $5 \times$ $10^{4}$ cells/well in a six-well plate, at $37^{\circ} \mathrm{C}$ with or without TMT for $24 \mathrm{~h}$ to determine intracellular ROS level. The probe was added to the culture medium and washed three times with PBS. Images were obtained after $30 \mathrm{~min}$ of incubation (IX71, Olympus, Japan). Fluorescence intensity was also detected. $\mathrm{N} 2 \mathrm{a}$ cells $\left(10^{4}\right.$ cells/well in a 96-well plate) were incubated with different concentrations of TMT for $24 \mathrm{~h}$. After loading the probes for $30 \mathrm{~min}$, intoxicated cells were washed three times with PBS. Fluorescence intensity was examined at Ex = $488 \mathrm{~nm}$ and $\mathrm{Em}=525 \mathrm{~nm}$ by using a microplate reader.

2.8. Lipid Peroxidation Measurement. MDA content was determined by double heating method, which is based on colorimetric determination of the purple color generated by the reaction of thiobarbituric acid (TBA) with MDA. The collected cells were mixed with TBA $(10 \% \mathrm{w} / \mathrm{v})$ solution and then boiled for $15 \mathrm{~min}$. The samples were centrifuged at $3000 \mathrm{rpm}$ for $10 \mathrm{~min}$ and the supernatant was transferred to a new tube and reacted with the TBA $(0.67 \% \mathrm{w} / \mathrm{v})$ solution. After boiling for $15 \mathrm{~min}$, the samples were cooled to room temperature and absorbance was determined at $532 \mathrm{~nm}$ with a microplate reader.

2.9. Antioxidant Determination. SOD activity was measured based on the inhibition extent of amino blue tetrazolium formazans in the mixture of nicotinamide adenine dinucleotide, phenazine methosulphate, and nitroblue tetrazolium. The color intensity of chromogen was determined at $560 \mathrm{~nm}$. Activity unit was defined as the number of enzymes that inhibited $50 \%$ of NBT reduction per milligram of protein.

2.10. Western Blot Analysis. Cells were lysed in RIPA lysis buffer containing 1\% PMSF. Total proteins were obtained through centrifugation. After quantification of protein concentration by using the BCA method, the total proteins were electrophoresed in $12 \%$ SDS-PAGE gels and transferred onto nitrocellulose filter membranes. The membranes were blocked with $5 \%$ BSA for $1.5 \mathrm{~h}$, and the blots were incubated with primary antibodies against GSK- $3 \beta$, p-GSK- $3 \beta$, Akt, pAkt, CyclinD1, C-Myc, Gli1, Shh, Bcl-2, Bax, and GAPDH $(1: 1000)$ at $4^{\circ} \mathrm{C}$ overnight. The membranes were washed three times with TBST for $5 \mathrm{~min}$ each, incubated with goat antirabbit $(1: 2500)$ IgG labeled with horseradish peroxidase for $1 \mathrm{~h}$, and then washed. Immunoreactive proteins were detected using the ECL detection system, and densitometric analysis of immunoblots was performed with the Gel pro 3.0 software. GAPDH was used as the protein loading control.

2.11. Caspase-3 Activity Assay. Caspase-3 activity was measured through the cleavage of the chromogenic caspase substrate, namely, acetyl-Asp-Glu-Val-Asp p-nitroanilide (AcDEVD-pNA). Approximately $50 \mu \mathrm{g}$ of the total protein was added into a reaction buffer containing Ac-DEVD-pNA $(2 \mathrm{mM})$ and incubated for $2 \mathrm{~h}$ at $37^{\circ} \mathrm{C}$. Absorbance of the yellow pNA cleaved from the corresponding precursor was spectrometrically determined at $405 \mathrm{~nm}$. Specific caspase activity was normalized to the total protein concentration of cell lysates and then expressed as fold increase over baseline caspase activity, which was determined from control cells cultured in DMEM with 10\% FBS or vehicle treated control cells.

2.12. Statistical Analysis. All results were expressed as mean \pm SD. All experiments were performed independently at least four times. Statistical analysis was conducted with SPSS18.0 software. Means were compared by one-way analysis of variance, and results between groups were compared using the Bonferroni test. Gait score was analyzed using MannWhitney $U$ test. Significance was defined at $P<0.05$.

\section{Results}

3.1. Protective Effect of LBP on Cytotoxicity Induced by TMT in N2a Cells. Cytotoxicity of TMT on N2a cells was determined by MTT method. As shown in Figure 1(a), exposure to different concentrations of TMT $(0.46875 \sim 120 \mu \mathrm{M})$ for $24 \mathrm{~h}$ dose-dependently reduced cell viability. By contrast, $300 \mu \mathrm{g} / \mathrm{mL}$ LBP significantly enhanced cell viability induced by treatment with $3.75 \mu \mathrm{M}$ TMT (Figures $1(\mathrm{a})$ and $1(\mathrm{~b})$ ). The cytotoxicity of TMT and the effect of LBP were also confirmed through morphological observation (Figure 1(c)). Under an inverted light microscope, the cells were retracted and rounded after exposure to different concentrations of TMT $(1.875,3.75$, and $7.5 \mu \mathrm{M})$ for $24 \mathrm{~h}$. Morphological changes were observed in N2a cells treated with $300 \mu \mathrm{g} / \mathrm{mL}$ LBP and $3.75 \mu \mathrm{M}$ TMT. These results indicated that cell viability was inhibited by TMT treatment, and LBP played a protective role in TMT-induced cell death.

3.2. LBP Attenuates N2a Cells Apoptosis Caused by TMT. DNA damage induced by different concentrations of TMT $(1.875,3.75$, and $7.5 \mu \mathrm{M})$ and LBP intervention were determined by Hoechst33258 staining in N2a cells (Figure 2(a)). DNA condensation and fragmentation occurred in N2a cells treated with 3.75 and $7.5 \mu \mathrm{M}$ TMT for $24 \mathrm{~h}$. Meanwhile, these 


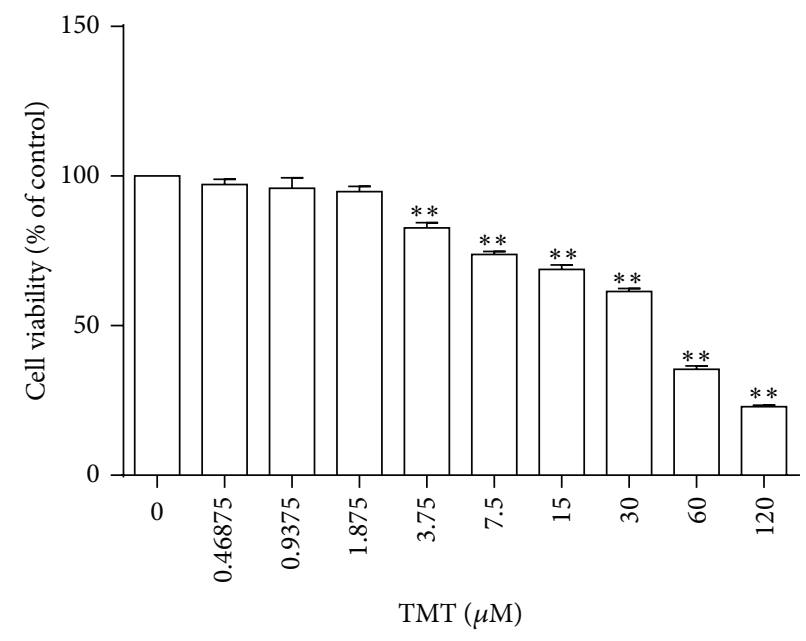

(a)
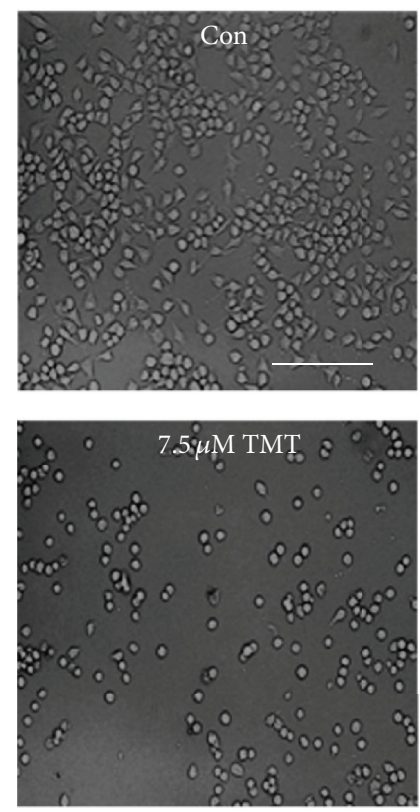

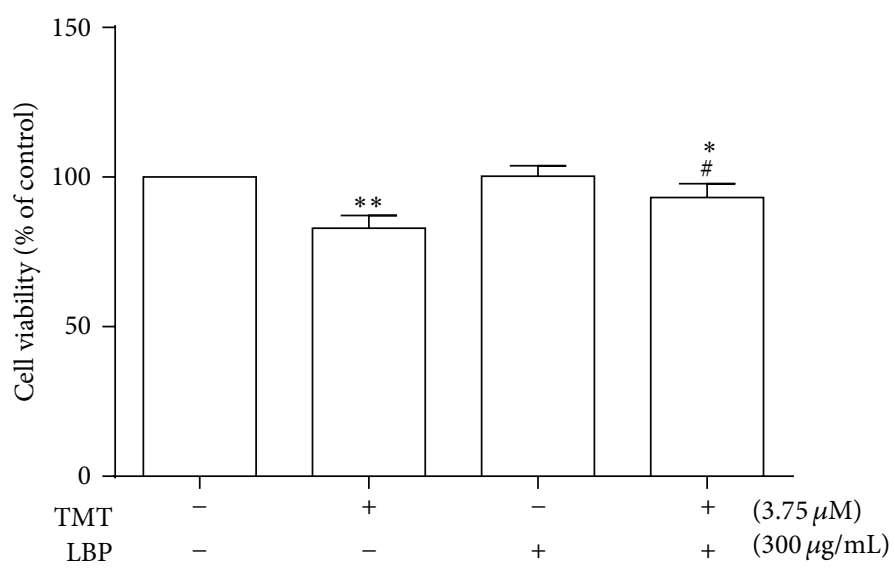

(b)
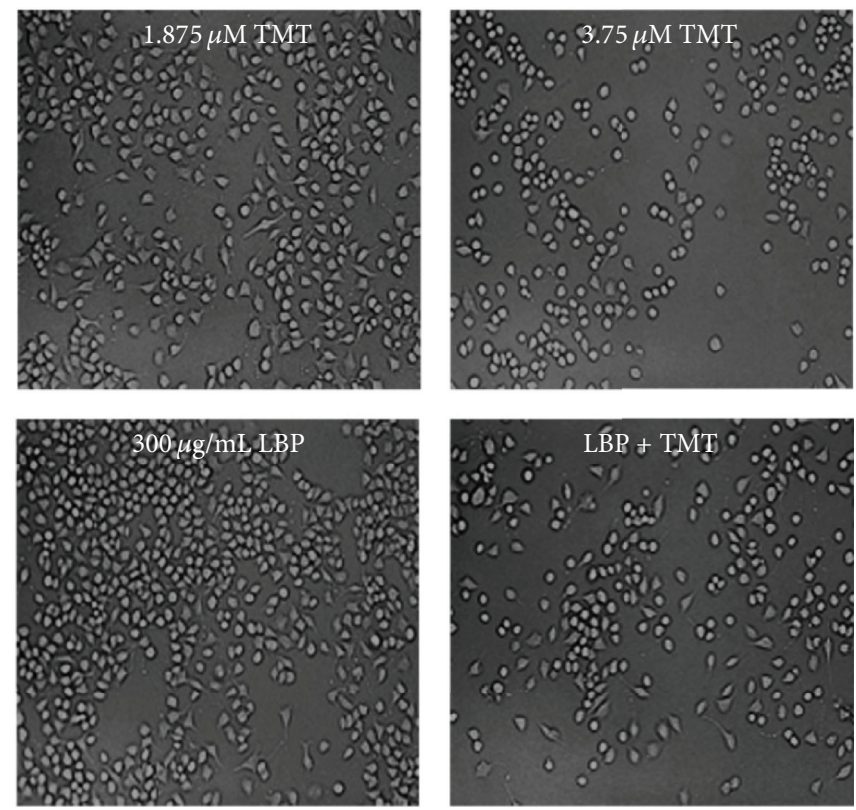

(c)

FIGURE 1: Cytotoxicity of TMT on N2a cells. N2a cells were treated with different concentrations of TMT $(0.46875 \sim 120 \mu \mathrm{M})$ for $24 \mathrm{~h}$. Cell viability was detected by MTT assay as described in Section 2 (a). Cells were treated with or without $300 \mu \mathrm{g} / \mathrm{mL} \mathrm{LBP}$ and $3.75 \mu \mathrm{M}$ TMT for $24 \mathrm{~h}$, and cell viability was also determined by MTT assay (b). The morphological changes in N2a cells after TMT and/or LBP treatment for $24 \mathrm{~h}$ were observed under an inverted light microscope, scale bar: $50 \mu \mathrm{m}$ (c). Cell survival rate was calculated and represented as mean \pm SD $(n=6) .{ }^{*} P<0.05,{ }^{* *} P<0.01$ compared with the control group; ${ }^{*} P<0.05$ compared with the TMT group.

apoptosis features and TMT-induced morphological alterations were inhibited by LBP at a concentration of $300 \mu \mathrm{g} / \mathrm{mL}$. Western blot analysis showed that incubation with $7.5 \mu \mathrm{M}$ TMT for $24 \mathrm{~h}$ significantly decreased $\mathrm{Bcl}-2$ protein expression and increased Bax protein level (Figures 2(b) and 2(c)). However, in the cells cotreated with $300 \mu \mathrm{g} / \mathrm{mL} \mathrm{LBP}$ and $3.75 \mu \mathrm{M}$ TMT, Bcl-2 expression was upregulated, and Bax expression was downregulated $(P<0.01)$. Flow cytometry using FITC-conjugated PE and 7-AAD double staining assay was further employed to quantitatively determine apoptosis induced by TMT and the protective effect of LBP. As shown in Figure 2(d), TMT markedly enhanced apoptosis in N2a cells, compared with the control $(P<0.01)$ and LBP reduced the TMT-induced apoptosis $(P<0.05)$. The activity of caspase-3 significantly increased after TMT treatment for $24 \mathrm{~h}$, whereas LBP downregulated caspase- 3 activity $(P<$ $0.05)$. All results indicated TMT induced cell apoptosis in a concentration-dependent manner. Moreover, LBP effectively attenuated TMT-induced apoptosis (Figures 2(e) and 2(f)).

3.3. LBP Suppresses Oxidative Damage Induced by TMT in N2a Cells. In order to observe the effects of LBP on oxidative stress induced by different concentrations of TMT $(1.875,3.75$, and $7.5 \mu \mathrm{M})$ for $24 \mathrm{~h}$, ROS level was examined 

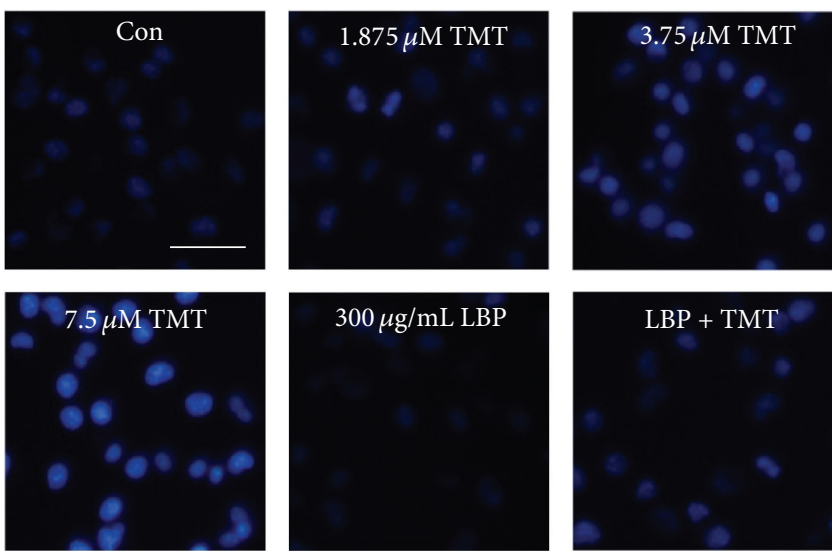

(a)
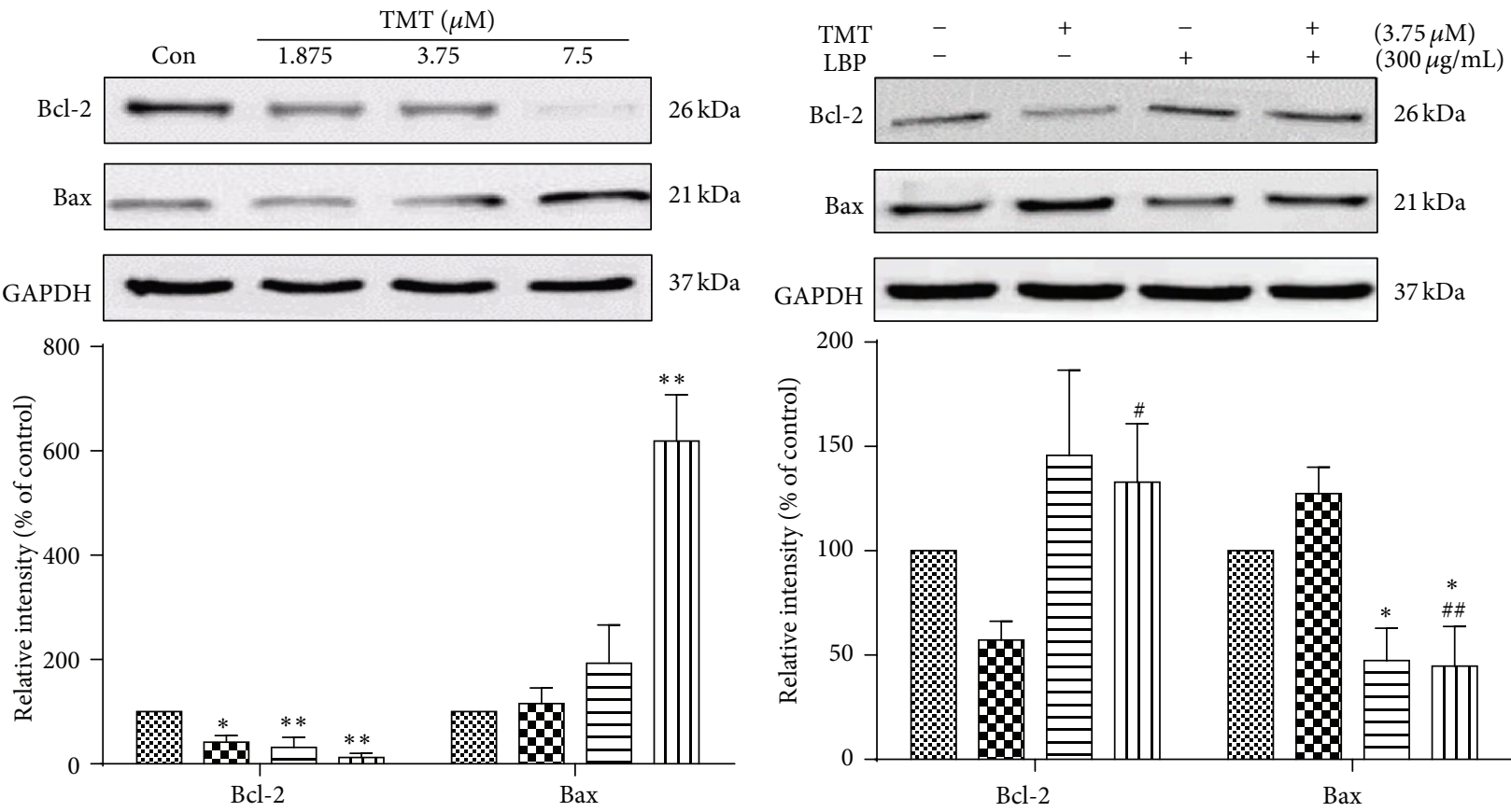

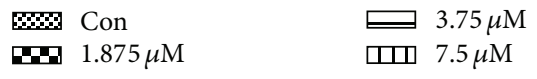

(b)

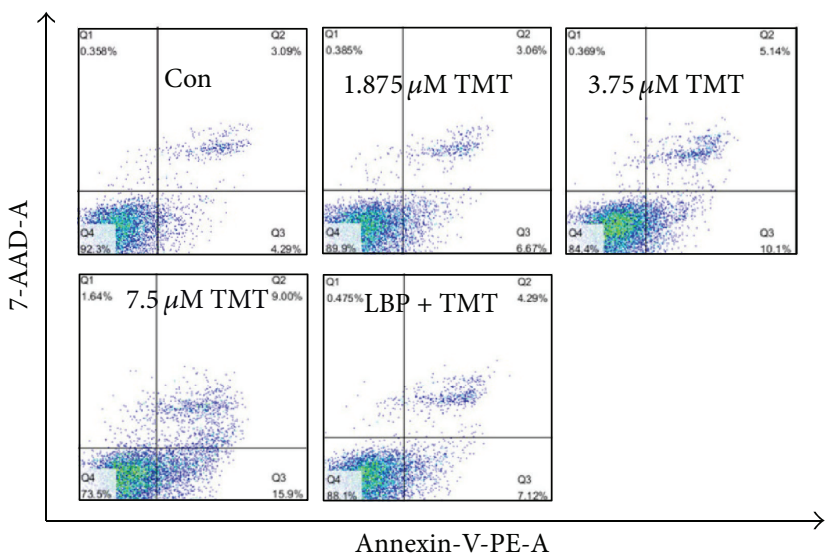

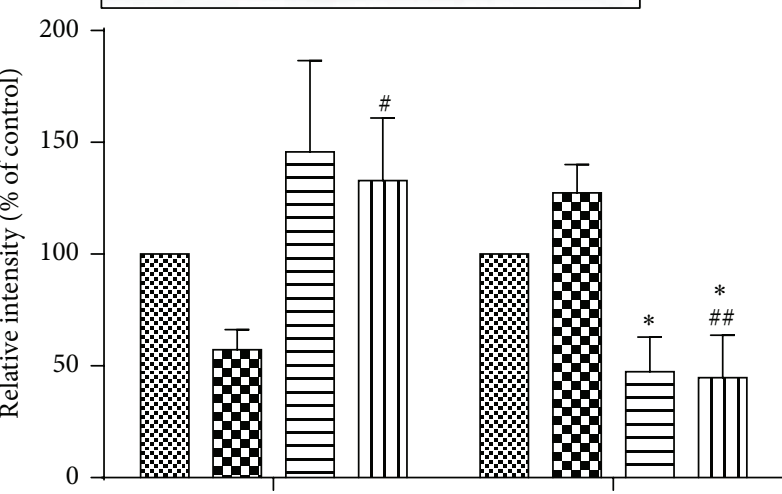

Bcl-2

Bax
\%8 Con

D. TMT

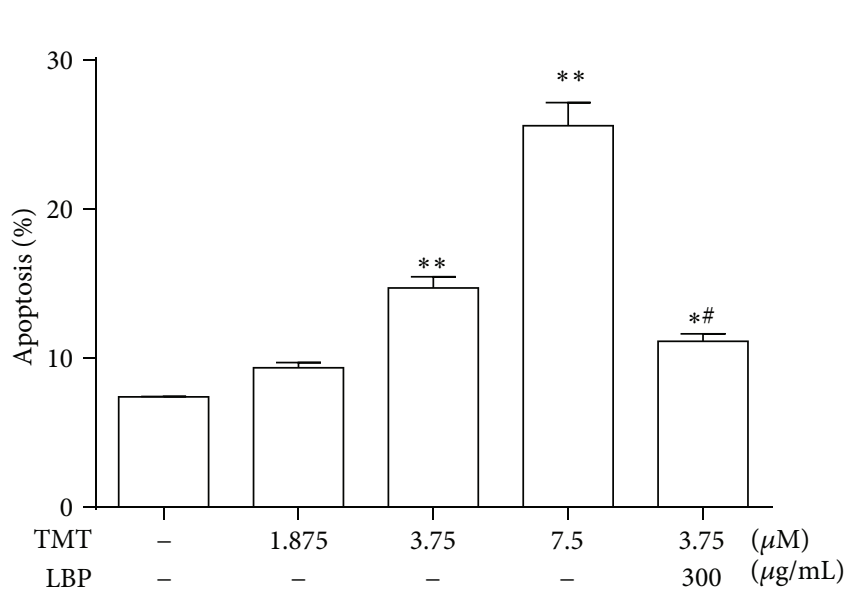

(d)

Figure 2: Continued. 


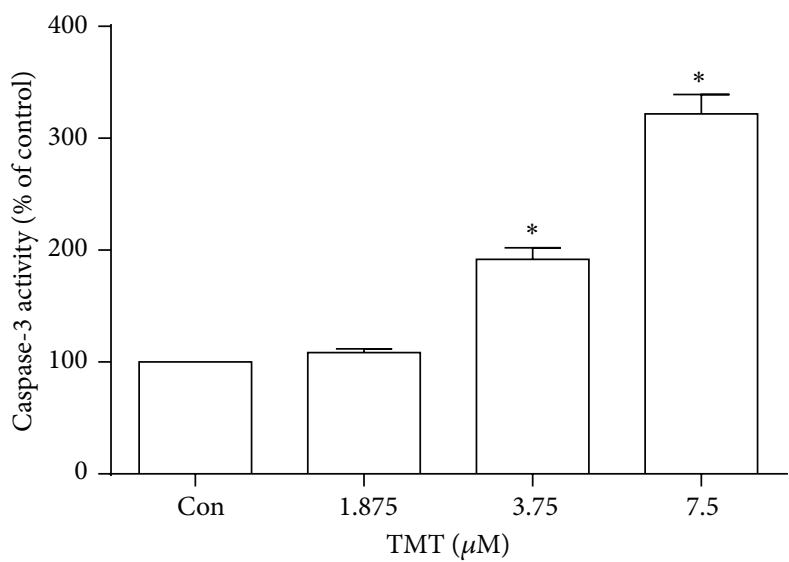

(e)

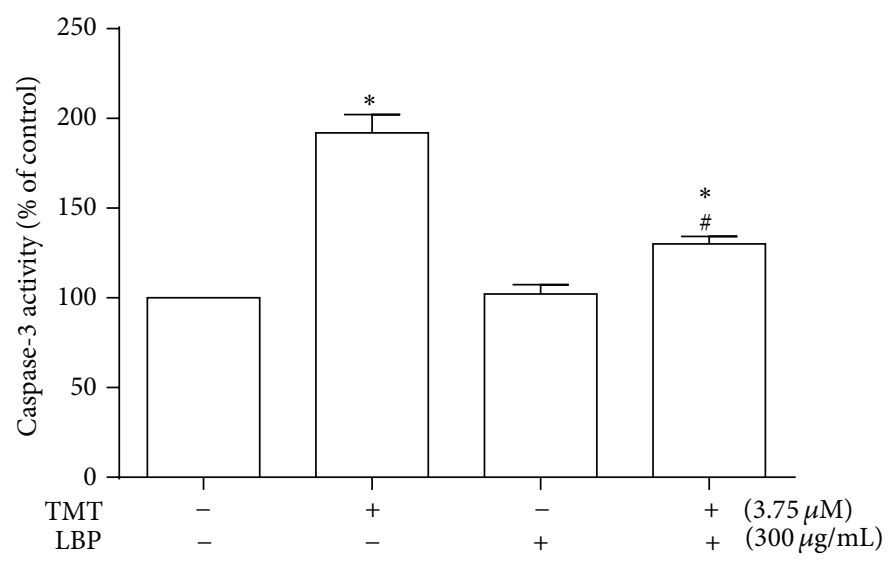

(f)

Figure 2: Protective effects of LBP on TMT-induced apoptosis in N2a cells. N2a cells were treated with different concentrations of TMT $(1.875,3.75$, and $7.5 \mu \mathrm{M})$ or cotreated with LBP $(300 \mu \mathrm{g} / \mathrm{mL})$ for $24 \mathrm{~h}$. DNA condensation and fragmentation in N2a cells were observed using Hoechst33258 staining under an inverted fluorescent microscope, scale bar: $25 \mu \mathrm{m}$ (a). Effects of TMT treatment on expression of Bcl-2 and Bax as determined through Western blot analysis. Total protein extracts were prepared after incubating the cells with 1.875 7.5 $\mu \mathrm{M}$ TMT for $24 \mathrm{~h}$ (b). Effects of LBP on the expression of Bcl-2 and Bax induced by TMT, as determined by Western blot analysis. Total protein extracts were prepared after incubating the cells with $300 \mu \mathrm{g} / \mathrm{mL}$ LBP and $3.75 \mu \mathrm{M}$ TMT for $24 \mathrm{~h}$ (c). All Western blot analysis results were expressed as fold changes of optical density, with GAPDH as the internal control. The mean protein expression of control is designated as 1 in the graph. After incubation with $1.875 \sim 7.5 \mu \mathrm{M}$ TMT for $24 \mathrm{~h}$, cells were collected and stained with PE-Annexin-V and 7-AAD for 5 min. Samples were analyzed by flow cytometry. The proportions of living and dead cells were determined by flow cytometric analysis of PE-Annexin-V and 7AAD-labeled cells. Live cells are unlabeled with PE and 7-AAD (Q3), whereas PE labeling (Q4) represents the population of early apoptosis. Cells showing PE and 7-AAD double labeling (Q2) represent those that have already died due to apoptosis. Ten thousand cells were analyzed in each sample. The percentages of the total apoptosis analyzed were determined (d). The effects of TMT alone (e) or TMT with LBP intervention (f) on caspase- 3 activity were assayed by ELISA method. Each bar represents mean $\pm \mathrm{SD}(n \geq 3) .{ }^{*} P<0.05,{ }^{* *} P<0.01$ compared with the control group; ${ }^{\#} P<0.05,{ }^{\# \#} P<0.01$ compared with the TMT-treated group.

in N2a cells through fluorescent dye DCFH-DA. As shown in Figure 3(b), ROS in the groups treated with 3.75 and $7.5 \mu \mathrm{M}$ TMT significantly increased compared with those in the control group $(P<0.01)$. Similar results were observed in immunofluorescence staining analysis (Figure 3(a)). After TMT treatment, MDA level significantly increased and SOD content decreased. These two targets showed a concentrationdependent trend in N2a cells (Figures 3(c) and 3(e)). However, when culture cells were cotreated with LBP and TMT for $24 \mathrm{~h}$, ROS and MDA levels significantly decreased (Figures $3(\mathrm{a}), 3(\mathrm{~b})$, and $3(\mathrm{~d})$ ), whereas SOD activity had a significant increase (Figure 3(f)). These results suggested that LBP exhibited a protective role in TMT-induced oxidative damage in N2a cells.

3.4. Inhibition of Shh and PI3K/Akt Signaling Pathways by TMT in N2a Cells. To determine whether the Shh and PI3K/Akt signaling pathways regulate TMT-induced apoptosis, we determined the levels of Shh, Glil, and p-Akt through Western blot analysis. Meanwhile, p-GSK-3 $\beta$, CyclinD1, and $\mathrm{C}-\mathrm{Myc}$ were evaluated to determine the downstream effects of signaling pathways through Western blot analysis. The cells were incubated with different concentrations of TMT (1.875, 3.75, and $7.5 \mu \mathrm{M})$ for $24 \mathrm{~h}$. As shown in Figure 4, the levels of Shh, Glil, and p-Akt significantly decreased $(P<0.05)$, whereas those of $\mathrm{p}$-GSK-3 $\beta$, CyclinD1, and C-Myc, which are downstream proteins of Shh and PI3K/Akt signaling pathways, significantly decreased. Therefore, TMT treatment concentration-dependently inhibited the Shh and PI3K/Akt signaling pathways.

3.5. Effect of LBP on TMT-Induced Inhibition of Shh and PI3K/Akt Signaling in N2a Cells. N2a cells were cotreated with $3.75 \mu \mathrm{M}$ TMT and $300 \mu \mathrm{g} / \mathrm{mL}$ LBP for $24 \mathrm{~h}$ to clarify the effects of LBP on TMT-induced signaling inhibition. As shown in Figure 5(c), Western blot analysis results indicated that phosphorylated GSK- $3 \beta$, phosphorylated Akt, and Gli1 protein expression significantly increased, and C-Myc protein level significantly decreased in TMT and LBP treatment, compared with that in TMT alone treatment. GSK-3 $\beta$ was also partly inhibited in treatment with LBP $(P<0.05)$. These findings were confirmed through immunofluorescence staining analysis (Figures 5(a) and 5(b)). All the results demonstrated the protective effect of LBP in TMT-induced Shh and PI3K/Akt signaling inhibition.

3.6. Roles of Shh and PI3K/Akt Signaling Pathways in TMTInduced Apoptosis in N2a Cells. Shh and PI3K/Akt signaling pathways were inhibited using LY294002 and GDC-0449 to determine the effect of their inhibition on apoptosis induction. LY294002 acts as a highly selective inhibitor of PI3K in vivo, and GDC-0449 targets the Hedgehog signaling pathway by blocking the activities of Hedgehog-ligand cell surface receptors and suppressing Hedgehog signaling. 

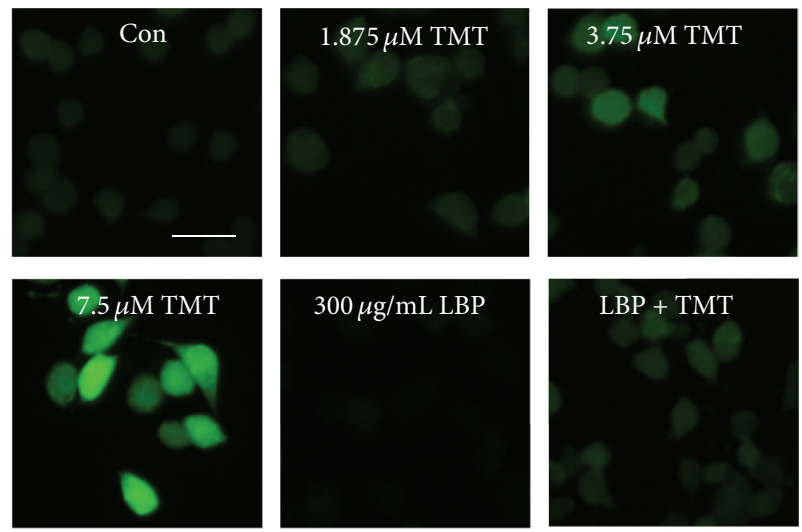

(a)

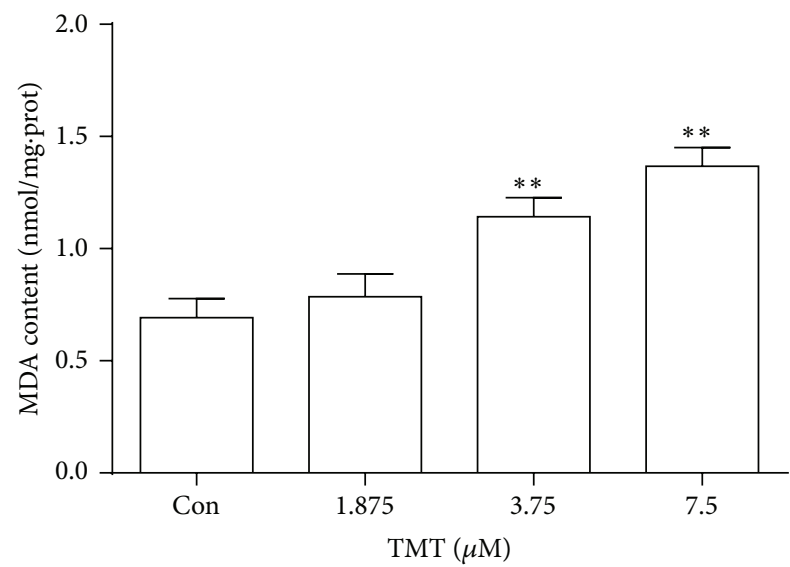

(c)

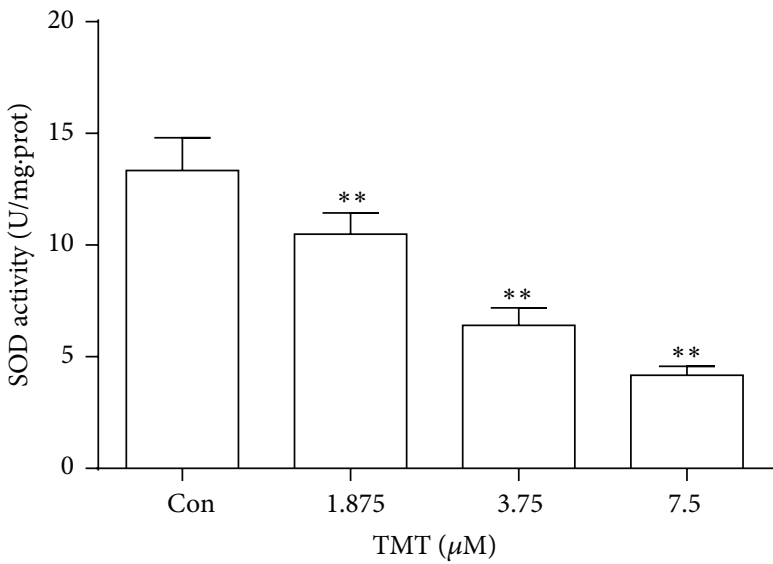

(e)

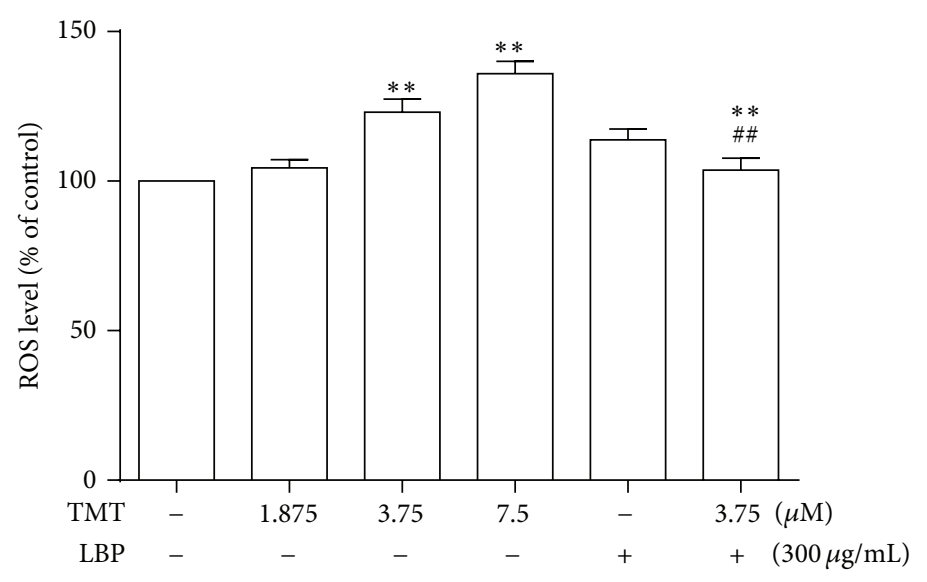

(b)

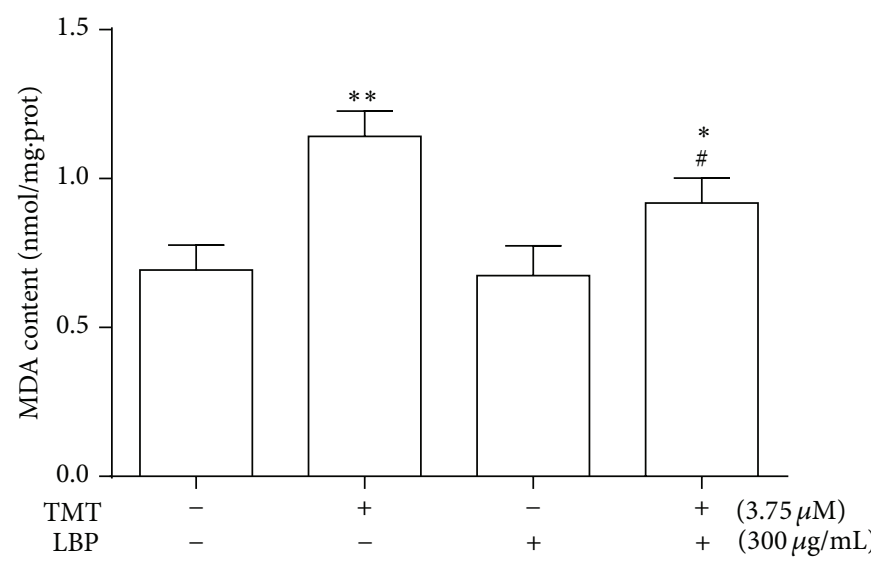

(d)

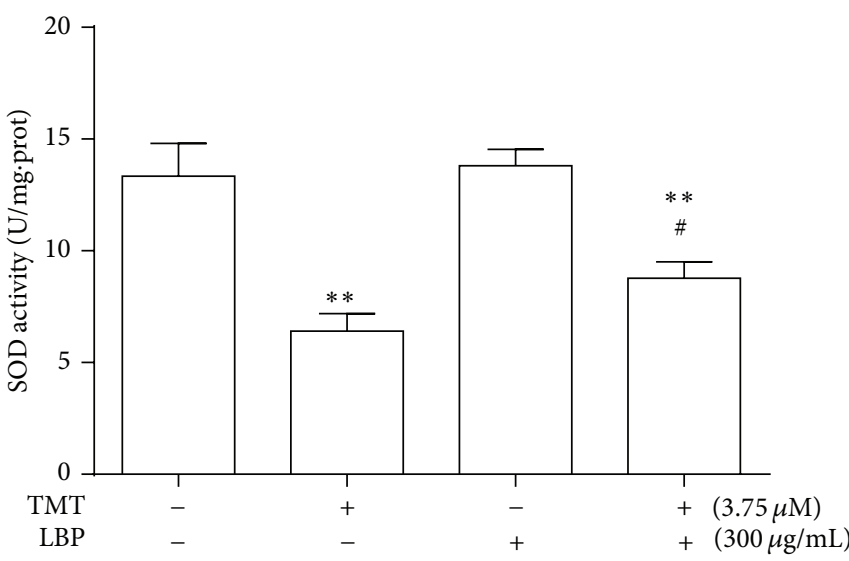

(f)

FIGURE 3: Effects of LBP on ROS, MDA generation, and SOD activity induced by TMT in N2a cells. Intracellular ROS was evaluated by DCFH-DA detection. Fluorescent photographs are shown after exposure to TMT $(1.875,3.75$, and $7.5 \mu \mathrm{M})$ and $3.75 \mu \mathrm{M}$ TMT with or without LBP $(300 \mu \mathrm{g} / \mathrm{mL})$ cotreatment for $24 \mathrm{~h}$, scale bar: $25 \mu \mathrm{m}$ (a). Furthermore, ROS, MDA, and SOD productions induced by TMT treatment $(0$, $1.875,3.75$, and $7.5 \mu \mathrm{M})$ alone for $24 \mathrm{~h}$ or $3.75 \mu \mathrm{M}$ TMT with LBP $(300 \mu \mathrm{g} / \mathrm{mL})$ were quantified $(\mathrm{b}-\mathrm{f})$. The results are expressed as mean $\pm \mathrm{SD}$ $(n=6) .{ }^{*} P<0.05,{ }^{* *} P<0.01$ compared with the control group; ${ }^{\sharp} P<0.05,{ }^{\# \#} P<0.01$ compared with the TMT-treated group.

Pretreatment with LY294002 $(1 \mathrm{~h}, 10 \mu \mathrm{M})$ and GDC-0449 $(2 \mathrm{~h}, 30 \mu \mathrm{M})$ promoted cytotoxicity induced by $3.75 \mu \mathrm{M}$ TMT (Figure 6(a)). Meanwhile, flow cytometry results showed that pretreatment with LY294002 and GDC-0449 significantly increased TMT-induced apoptosis (Figure 6(b)). Caspase-3 activity significantly increased in $3.75 \mu \mathrm{M}$ TMT exposure groups pretreated with inhibitors, compared with that in control group or TMT alone treatment group (Figures 6(c) 


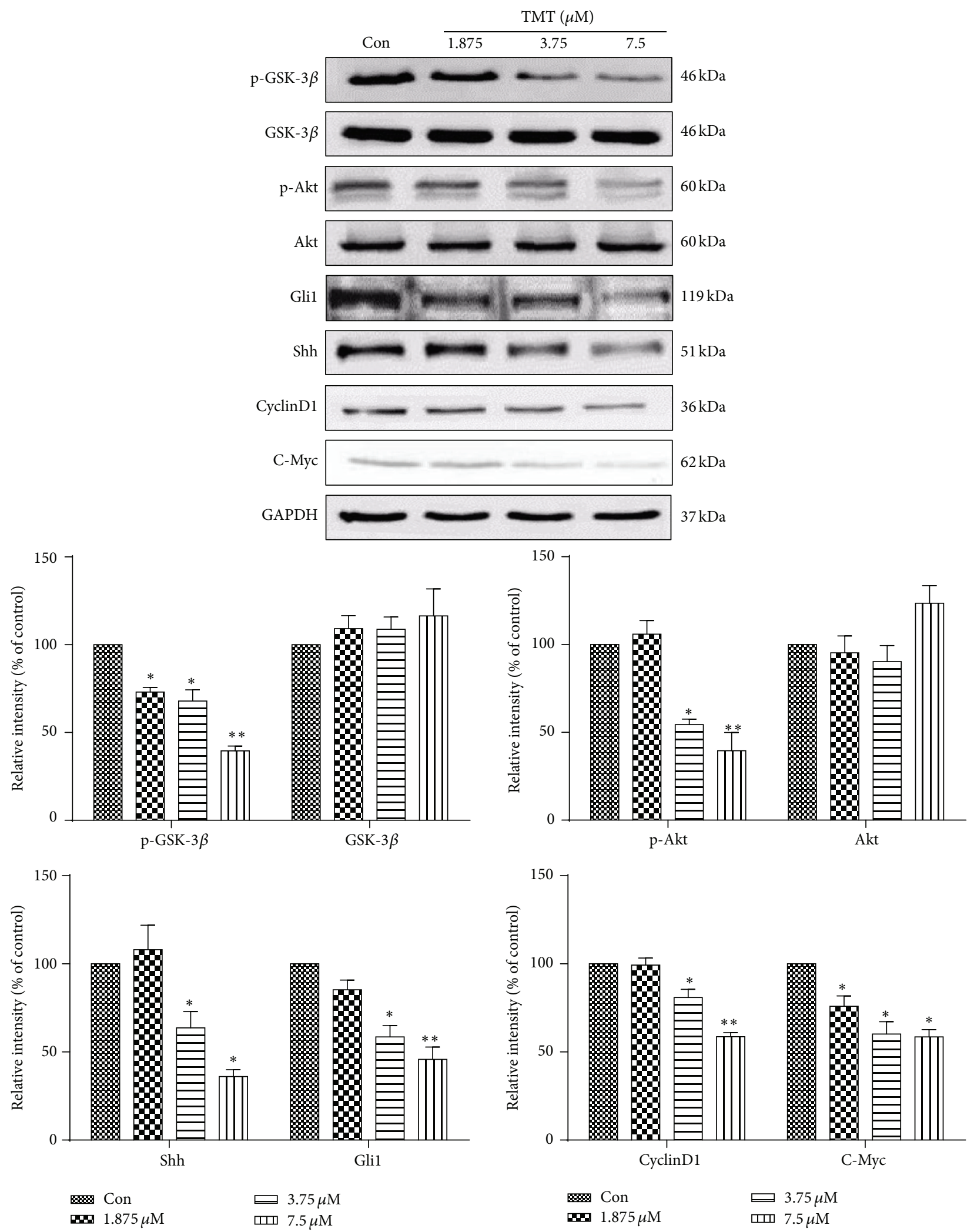

FIGURE 4: TMT-induced Shh and PI3K/Akt inhibition. N2a cells were incubated with 1.875, 3.75, and 7.5 $\mu$ M TMT for $24 \mathrm{~h}$. Different protein expressions levels were determined through Western blot analysis. The results are expressed as fold increases of optical density with the internal control. The mean protein expression of control group is designated as one in the graph. Each bar represents mean \pm SD $(n=3)$. ${ }^{*} P<0.05,{ }^{* *} P<0.01$ compared with the control group. 

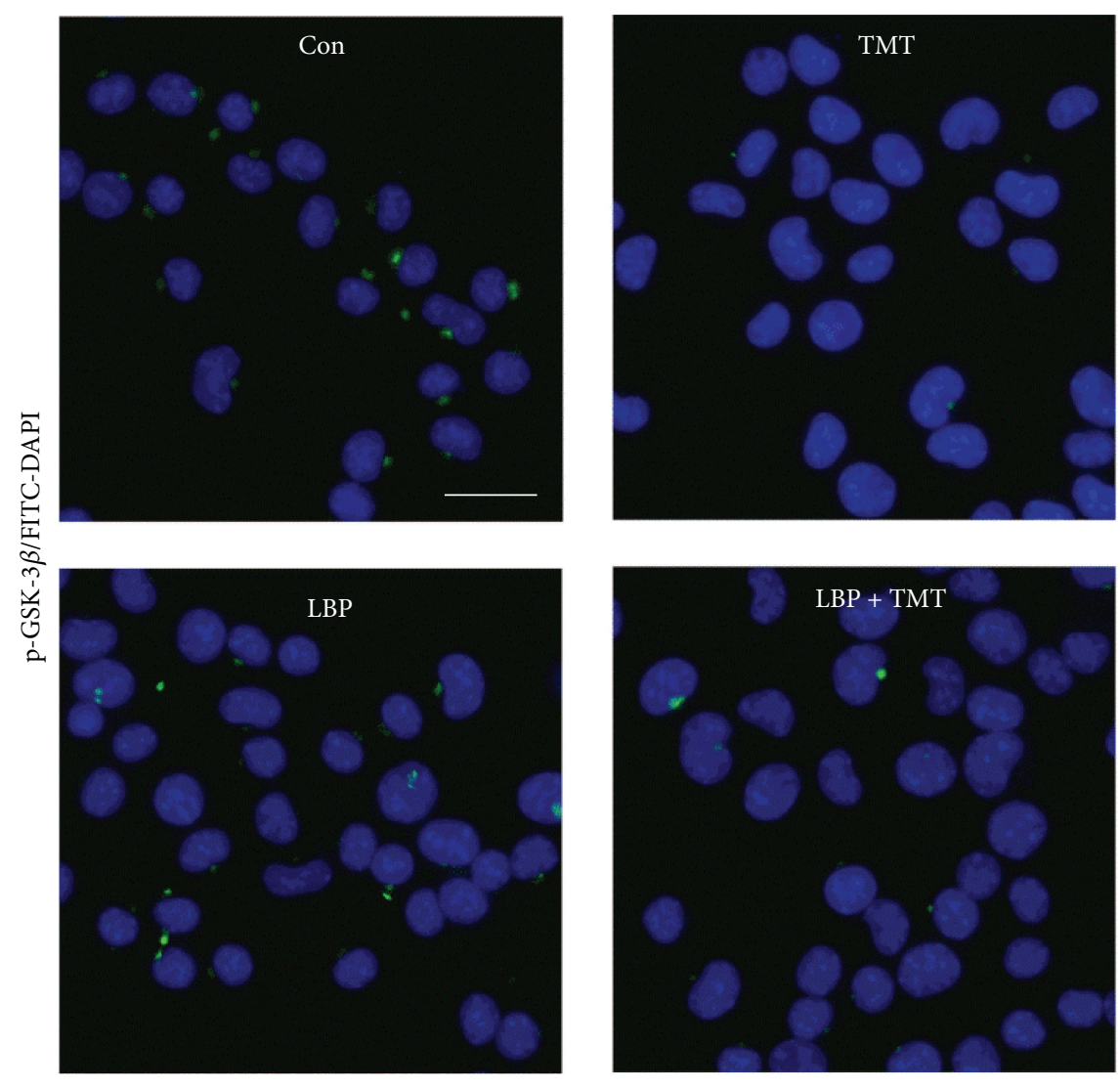

(a)
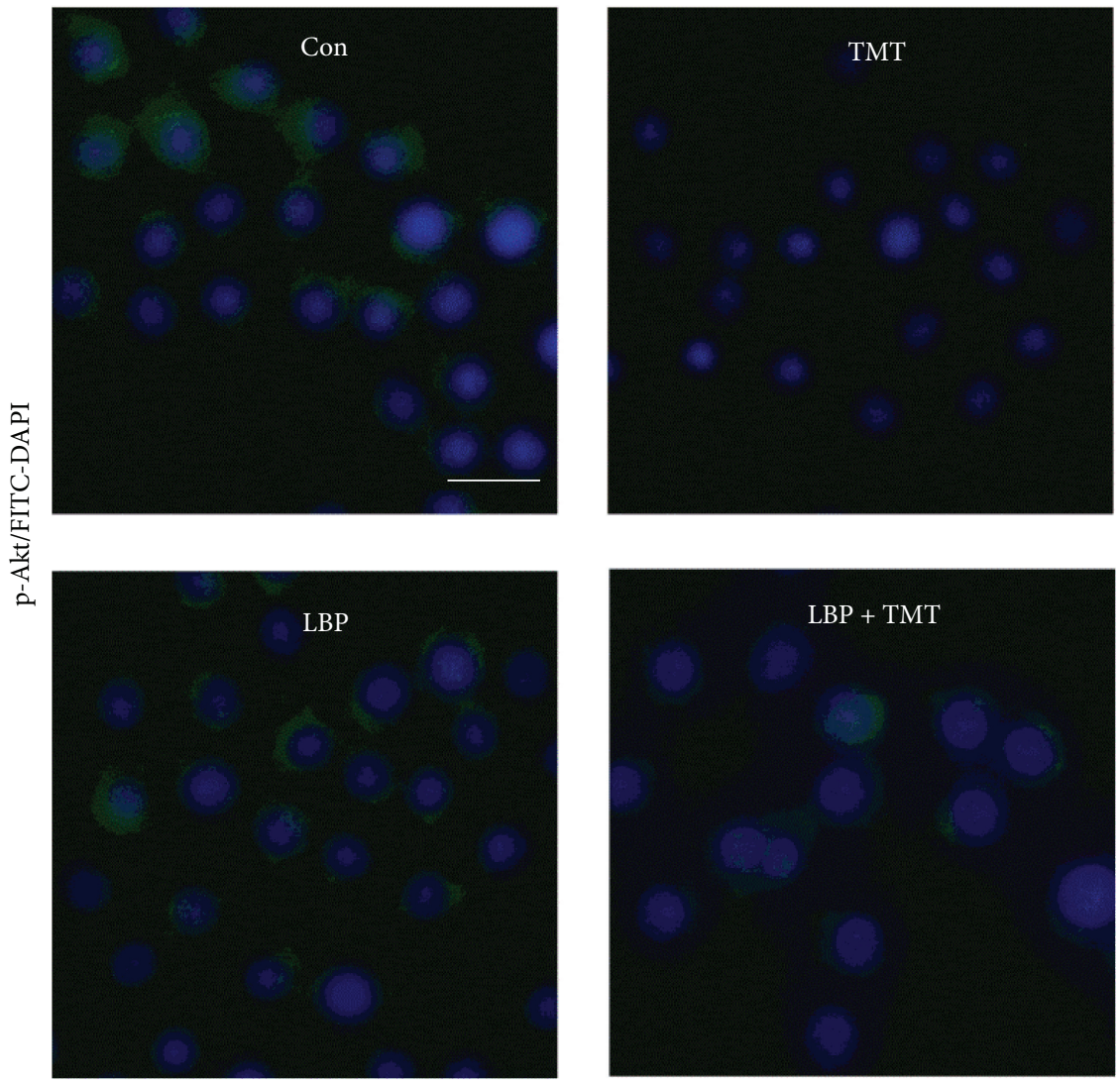

(b)

FIgure 5: Continued. 

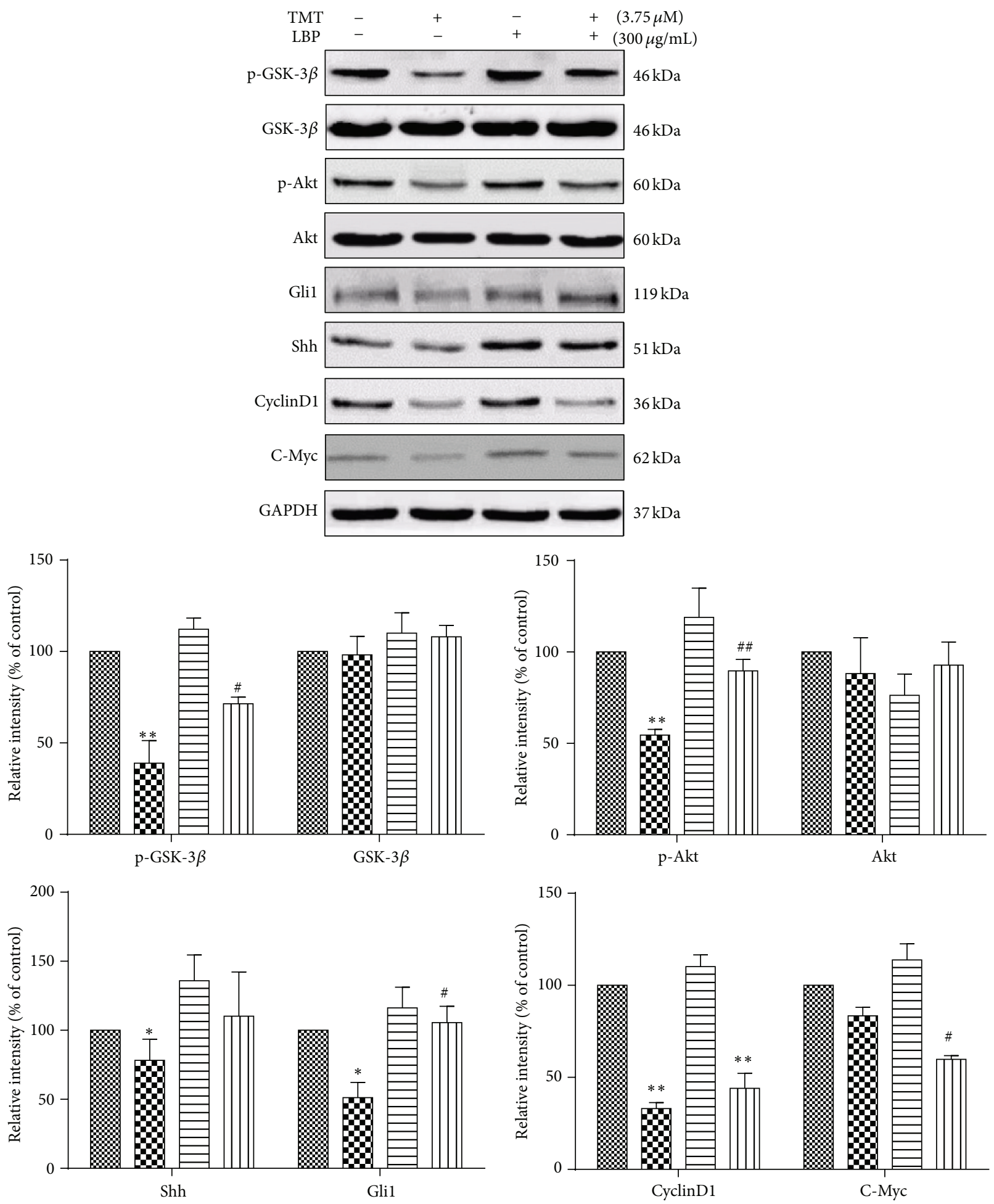

$$
\begin{aligned}
& \text { \% Con } \\
& \square \text { LBP } \\
& 1 \text { TMT سل TMT + LBP }
\end{aligned}
$$

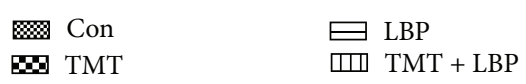

(c)

Figure 5: Effect of LBP on TMT-induced signaling inhibition. The cells were incubated with $300 \mu \mathrm{g} / \mathrm{mL}$ LBP and $3.75 \mu \mathrm{M}$ TMT for $24 \mathrm{~h}$. Fluorescent photographs are shown after exposure to TMT with or without LBP for $24 \mathrm{~h}$, scale bar: $25 \mu \mathrm{m}$ (a and b). Different protein levels expressions were determined through Western blot analysis. The results are expressed as fold increases of optical density with the internal control. The mean protein expression of control group is designated as one in the graph (c). Each bar represents $\operatorname{mean} \pm \operatorname{SD}(n=3)$. ${ }^{*} P<0.05$, ${ }^{* *} P<0.01$ compared with the control group; ${ }^{\#} P<0.05,{ }^{\# \#} P<0.01$ compared with the TMT-treated group. 


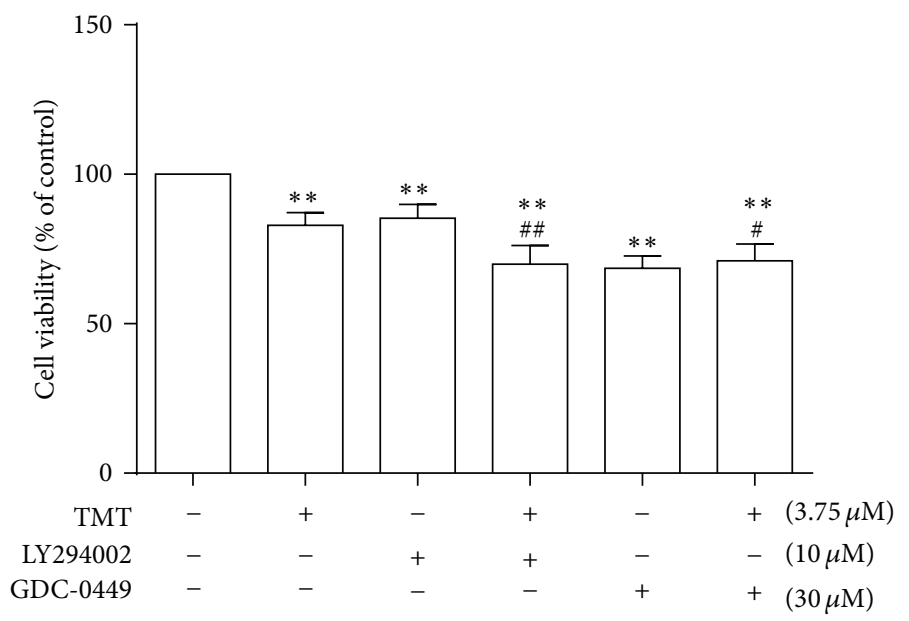

(a)

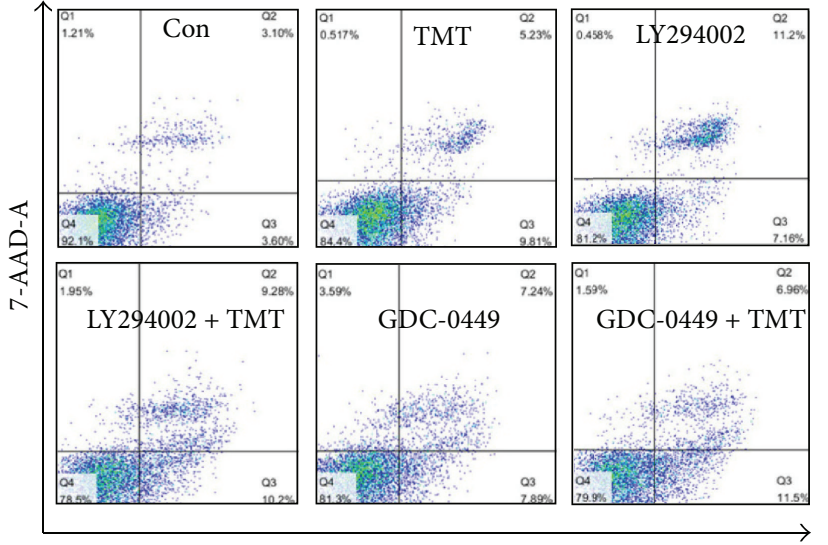

Annexin-V-PE-A

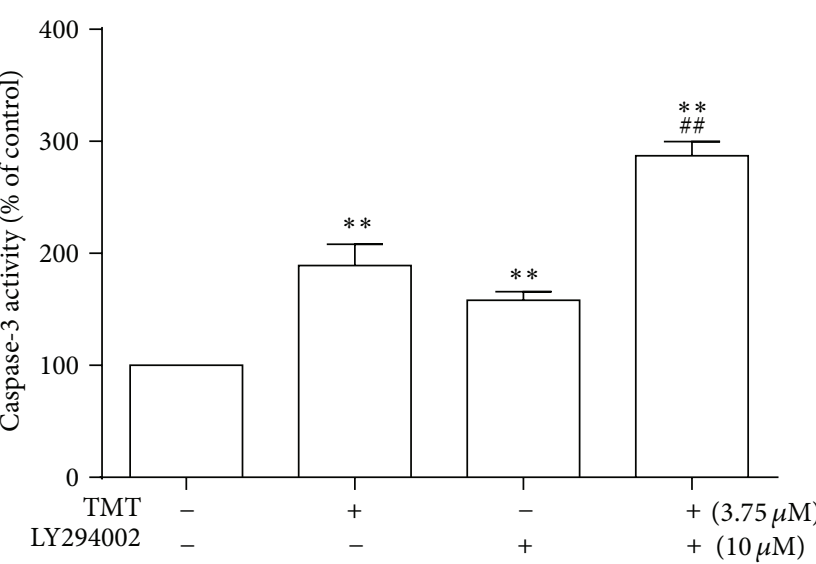

(c)

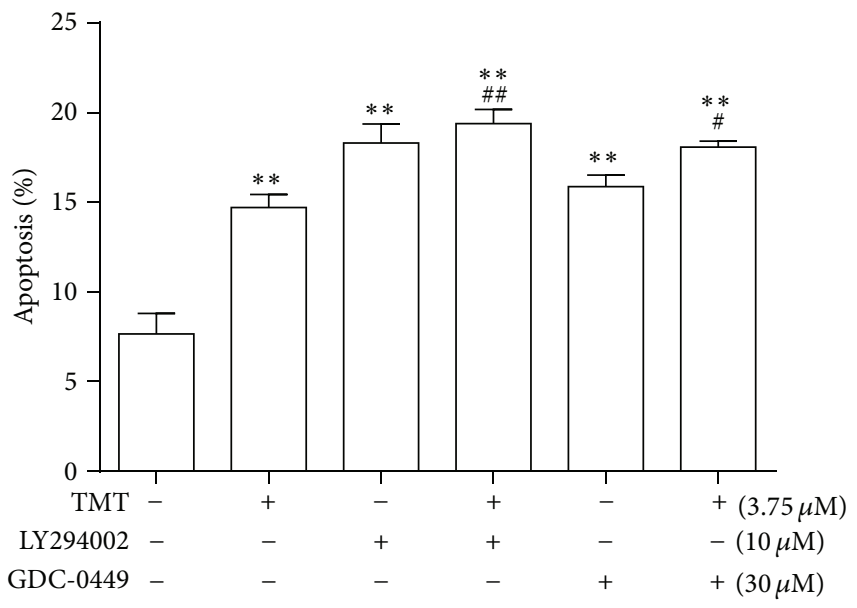

(b)

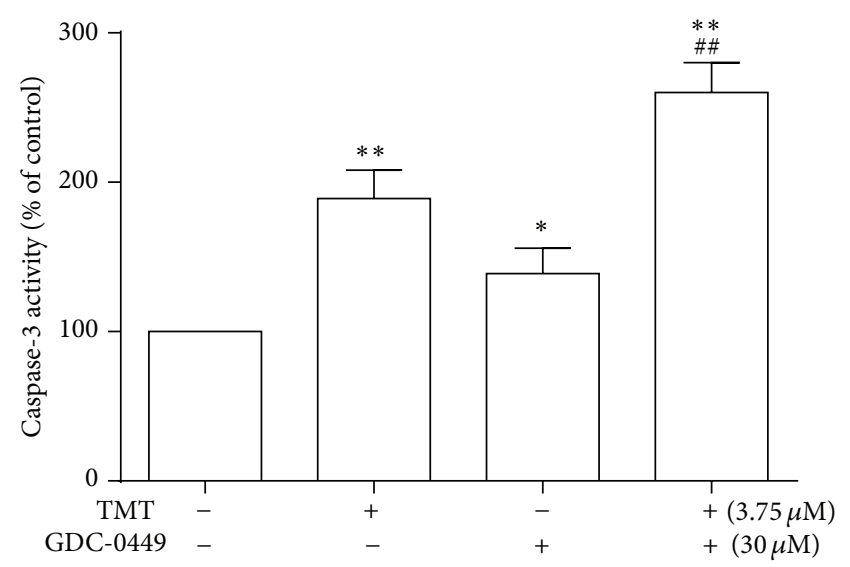

(d)

FIGURE 6: Effects of antagonists on TMT-induced apoptosis in N2a cells. N2a cells were pretreated with or without different inhibitors at different time points in the following concentrations: LY2940002, $10 \mu \mathrm{M}$; GDC-0449, $30 \mu \mathrm{M}$, followed by incubation with or without $3.75 \mu \mathrm{M}$ TMT for another $24 \mathrm{~h}$. Cell survival rate was calculated and represented as mean $\pm \operatorname{SD}(n=6)(\mathrm{a})$. Cells were collected and stained with $\mathrm{PE}-\mathrm{Ann}$ exin-V and 7-AAD for $5 \mathrm{~min}$. The samples were analyzed through flow cytometry. The percentage of apoptosis cells based on the total cell population analyzed was determined (b). Effects of inhibitors on TMT-treated N2a cells; caspase-3 activity was determined through ELISA (c and d). Each bar represents mean $\pm \mathrm{SD}(n \geq 3) .{ }^{*} P<0.05,{ }^{* *} P<0.01$ compared with the control group; ${ }^{\#} P<0.05,{ }^{\# \#} P<0.01$ compared with the TMT-treated group. 
and 6(d)). Hence, pretreatment with both inhibitors caused a statistical increase in apoptosis induced by TMT.

\subsection{Effects of Shh and PI3K/Akt Signaling Pathways on Oxida-} tive Stress Induced by TMT in N2a Cells. To confirm the role of Shh and PI3K/Akt signaling pathways on oxidative stress induced by $3.75 \mu \mathrm{M}$ TMT for $24 \mathrm{~h}$, we quantified the levels of ROS, MDA, and SOD. Figures $7(a)$ and $7(b)$ indicated that ROS level in groups, pretreated with LY294002 (1 h, $10 \mu \mathrm{M})$ and GDC-0449 $(2 \mathrm{~h}, 30 \mu \mathrm{M})$ inhibitors, significantly decreased compared with that in control group or TMTtreated group $(P<0.01)$. Consistently, MDA level significantly increased and SOD content decreased in N2a cells treated with inhibitors (Figures $7(\mathrm{c}), 7(\mathrm{~d}), 7(\mathrm{e})$, and $7(\mathrm{f})$ ). These data are consistent with the notion that inhibition of Shh and PI3K/Akt signaling pathways could activate TMTinduced oxidative damage.

3.8. Cross Talk between Shh and PI3K/Akt Signaling Pathways. To demonstrate the interaction between Shh and PI3K/Akt pathways, we used specific inhibitors and evaluated possible alteration of each pathway. N2a cells were incubated with inhibitors of Shh (GDC-0449) or PI3K/Akt (LY294002) for $2 \mathrm{~h}$ before $3.75 \mu \mathrm{M}$ TMT treatment for $24 \mathrm{~h}$. As shown in Figure 8, the inhibition of the PI3K/Akt signaling pathway with LY294002 significantly reduced Shh and GSK-3 $\beta$ protein expression compared with TMT treatment $(P<0.05)$. Meanwhile, GDC-0449 pretreatment significantly inhibited Glil protein expression compared with TMT alone exposure $(P<0.01)$ and had no significant effect on $\mathrm{p}-\mathrm{GSK}-3 \beta$ and $\mathrm{p}$-Akt protein expression. These results indicated that the inhibition of PI3K/Akt pathway could affect GSK-3 $\beta$ phosphorylation and the activation of Shh pathway.

\section{Discussion}

The study was focused on the signaling pathways that contributed to TMT-induced cell apoptosis. In particular, the protective effect of LBP and the roles of Shh and PI3K/Akt signaling pathways in TMT-induced N2a cells apoptosis were studied. Neuro-2a cell lines which derive from mouse neuroblastoma can express neuronal phenotype and are a common model for studies on the mechanism of nervous systemic disease [19].

TMT exposure exhibited evident cytotoxicity and decreased cell viability in $\mathrm{N} 2 \mathrm{a}$ cells in a dose-dependent manner. Thus, the doses of $1.875,3.75$, and $7.5 \mu \mathrm{M}$ were selected as TMT exposure concentrations in our study, and relatively similar concentrations were applied in our previous experiments [8]. But there was some slight difference in concentration choice, which may be due to different cytotoxicity of TMT on various species cell lines. Except for this, TMT was proved to induce apoptosis in N2a cells by significantly upregulating Bax expression, downregulating Bcl-2 expression, and increasing caspase- 3 activity. Oxidative stress is closely related not only to neurodegenerative disorders, but also to apoptosis $[4,20,21]$. In the study, TMT induced ROS generation and lipid peroxidation in N2a cells.
Thus, we infer that TMT regulates apoptotic related genes, activates caspase cascade, causes oxidative damage, and finally induces cell apoptosis.

$\mathrm{PI} 3 \mathrm{~K} / \mathrm{Akt}$ signaling is a membrane receptor signaling pathway related to intracellular transduction. Previous study showed that PI3K/Akt pathway could be involved in TMTinduced neuronal damage or apoptosis [22]. The pathway not only regulates various signaling molecules, but also is regulated by signaling molecules, particularly regulatory molecules, such as ROS $[23,24]$. Hence, ROS overproduction induced by TMT in N2a cells could be considered as a stimulus of PI3K/Akt pathway activation. Although some studies showed that TMT had a completely opposite effect on PI3K/Akt pathway [22, 25], TMT treatment in N2a cells inhibited Akt phosphorylation in the study. In addition, the inhibition of PI3K/Akt pathway by LY294002 increased ROS and MDA generations and decreased SOD levels, which enhanced oxidative damage and promoted cell apoptosis in N2a cells. Thus, it was confirmed that PI3K/Akt signaling pathway is a protective regulator in response to TMT exposure in N2a cells. TMT neurotoxicity on N2a cells may be related to blocking the protective signaling pathway PI3K/Akt.

Sonic Hedgehog (Shh) pathway plays a vital role in brain development, neural stem cell proliferation, and neuronal regeneration and repair [26, 27]. The activity of the Shh signaling pathway targeting genes expression is controlled by the Gli family (Gli1, Gli2, and Gli3). The multiplication and proliferation of effector molecules (such as CyclinD1 and C-Myc) in tumor cells are proved to be the target genes or downstream molecules of Hedgehog signaling pathway [28]. There are studies showing that the activation of Shh signaling protects cortical neurons against oxidative stress, suggesting a potential role of Shh for clinic treatments of brain ischemia and neurodegenerative disorders [12]. Hence, Shh signaling change in our model was mainly studied. In our study, Shh pathway was suppressed by TMT treatment, confirming that Glil, CyclinD1, and C-Myc expression significantly decreased in N2a cells. The suppression of Shh pathway reduced cell viability and enhanced oxidative damage and apoptosis, which were similar to PI3K/Akt inhibition. Thus, Shh pathway also had a protective effect on TMT-induced neurotoxicity in $\mathrm{N} 2 \mathrm{a}$ cells, just like PI3K/Akt. We therefore infer that the reasons why TMT inhibited Shh expression may be excessive ROS generation, lipid peroxidation, and TMT-induced PI3K/Akt signaling pathway blockage, which destroys the natural repair system of body.

GSK-3 $\beta$ is not only a downstream effector kinase of PI3K/Akt pathway, but also an important kinase of Shh signaling pathway [29]. GSK-3 $\beta$ is suggested as one of the key regulators of the Gli family [10]. We drew close attention to investigate the relationship between Shh and PI3K/Akt pathways by using each of the inhibitors GDC0449 and LY294002 in TMT-treated N2a cells. Results suggested that TMT inhibited GSK-3 $\beta$ phosphorylation which activated GSK-3 $\beta$ signaling. The distribution of $\mathrm{p}-\mathrm{GSK}$ $3 \beta$ was throughout the cytoplasm, whereas $\mathrm{p}$-Akt was distributed in cytoplasm with point shape. Shh pathway was inhibited when PI3K/Akt pathway was blocked. Similarly, 


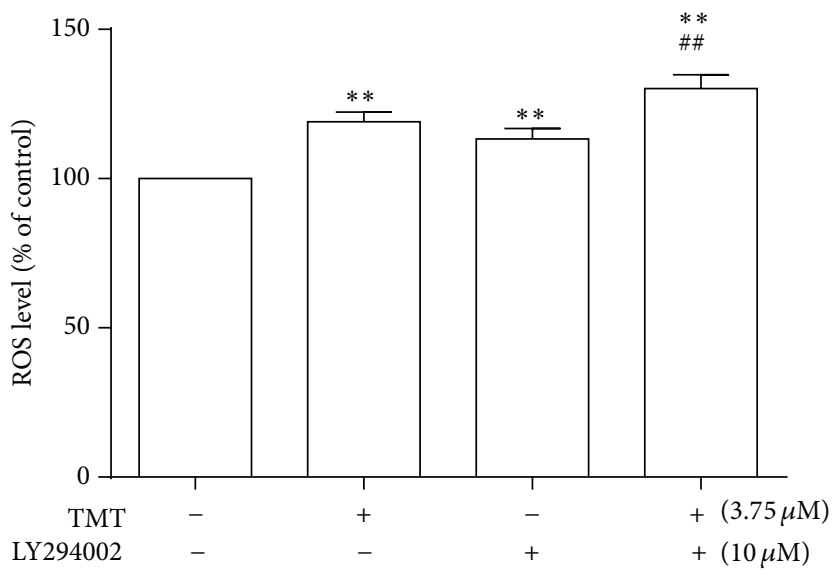

(a)

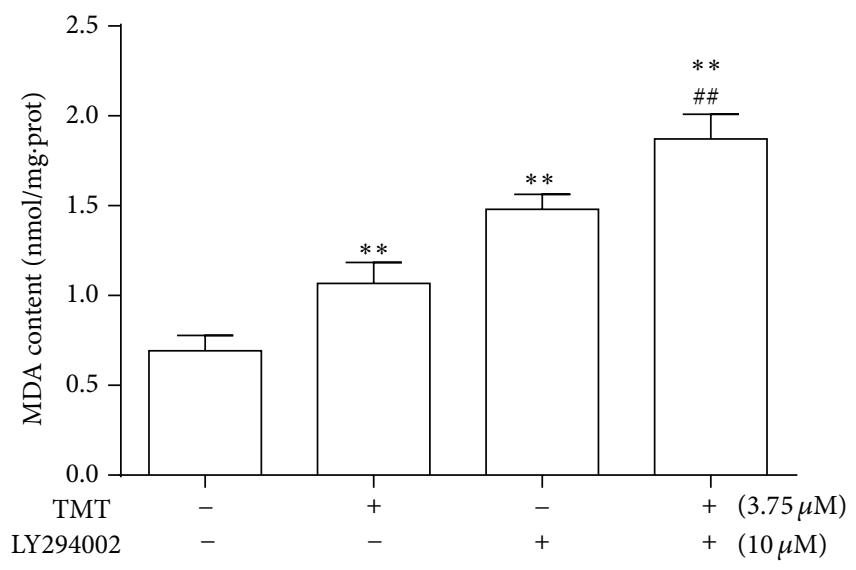

(c)

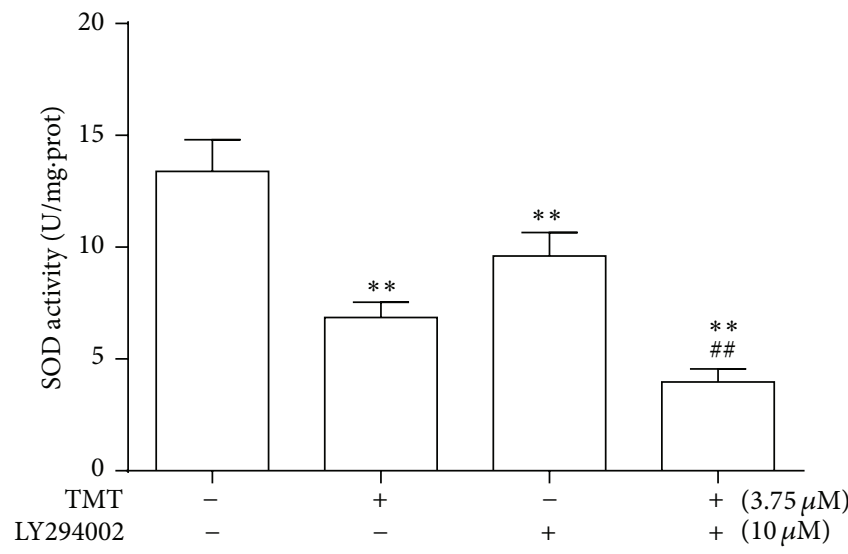

(e)

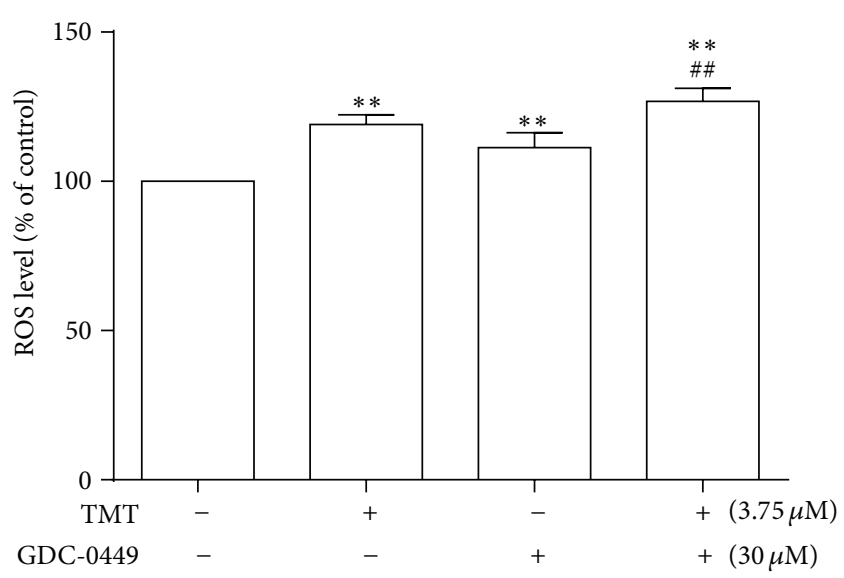

(b)

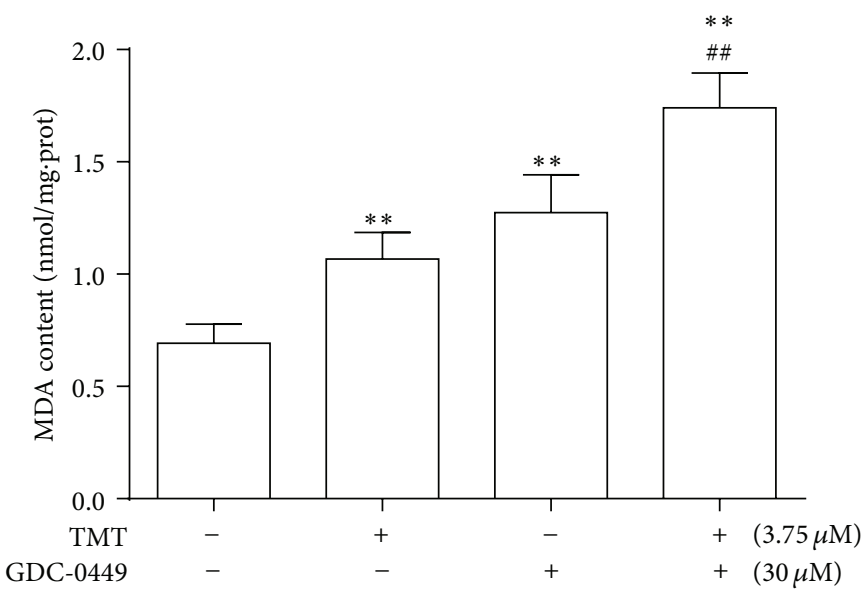

(d)

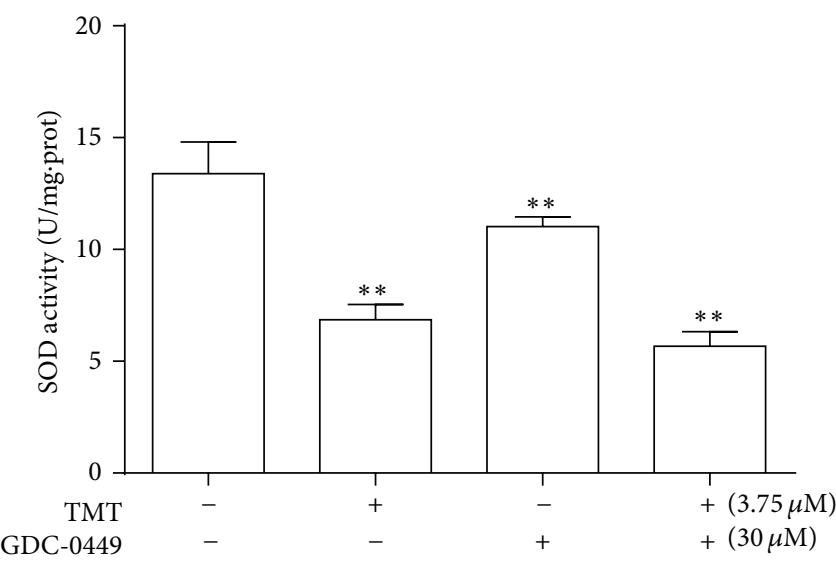

(f)

FIGURE 7: Effects of antagonists on ROS, MDA generation, and SOD activity caused by TMT in N2a cells. Cells were cultured with $3.75 \mu$ M TMT, pretreated with or without different inhibitors at different time points in different concentration (LY2940002, 10 $\mu$ M; GDC-0449, $30 \mu \mathrm{M})$, and quantified to evaluate ROS, MDA, and SOD productions. Results are expressed as mean $\pm \operatorname{SD}(n=6) .{ }^{*} P<0.05$, ${ }^{* *} P<0.01$ compared with the control group; ${ }^{\#} P<0.05,{ }^{\# \#} P<0.01$ compared with the TMT-treated group.

Akt phosphorylation was decreased when Shh pathway was inhibited. The similar findings in other studies showed that Shh acted on PI3K/Akt, and Akt had a regulatory role in the Shh signaling pathway [30-33]. In order to clarify whether
GSK-3 $\beta$ provided a bridge between Shh and PI3K/Akt, GSK$3 \beta$ phosphorylation was investigated. It was found that phosphorylated GSK-3 $\beta$ significantly decreased when PI3K/Akt was blocked by PI3K inhibitor. Meanwhile, the blockage of 

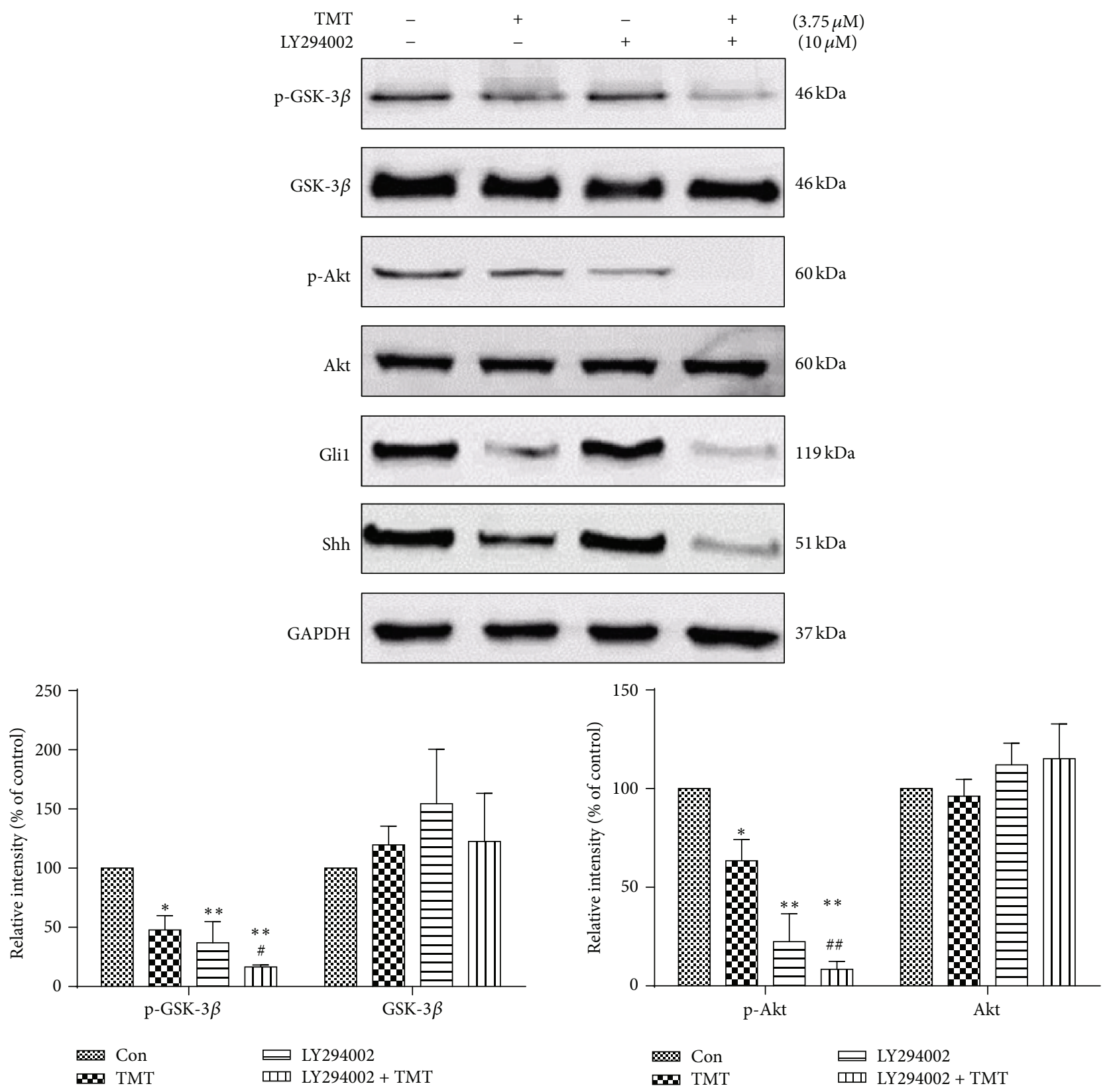

$$
\begin{array}{lll}
\text { 80 Con } & \text { LY294002 } \\
\text { TMT } & \text { एव } & \text { LY294002 + TMT }
\end{array}
$$
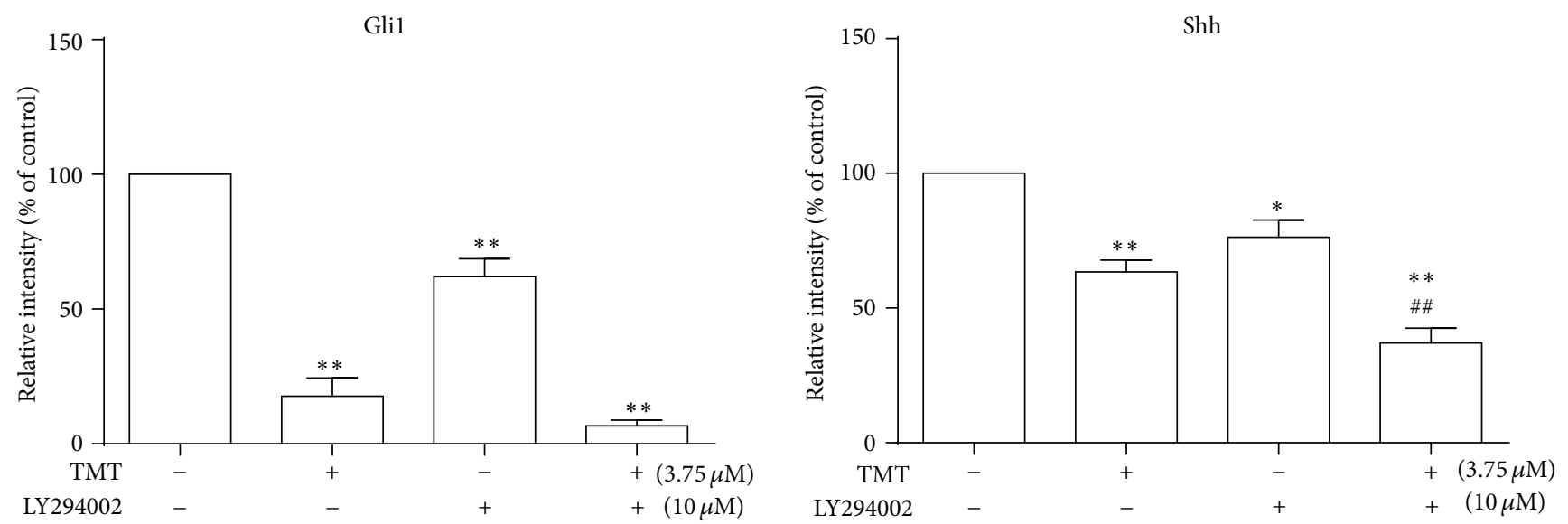

(a)

Figure 8: Continued. 

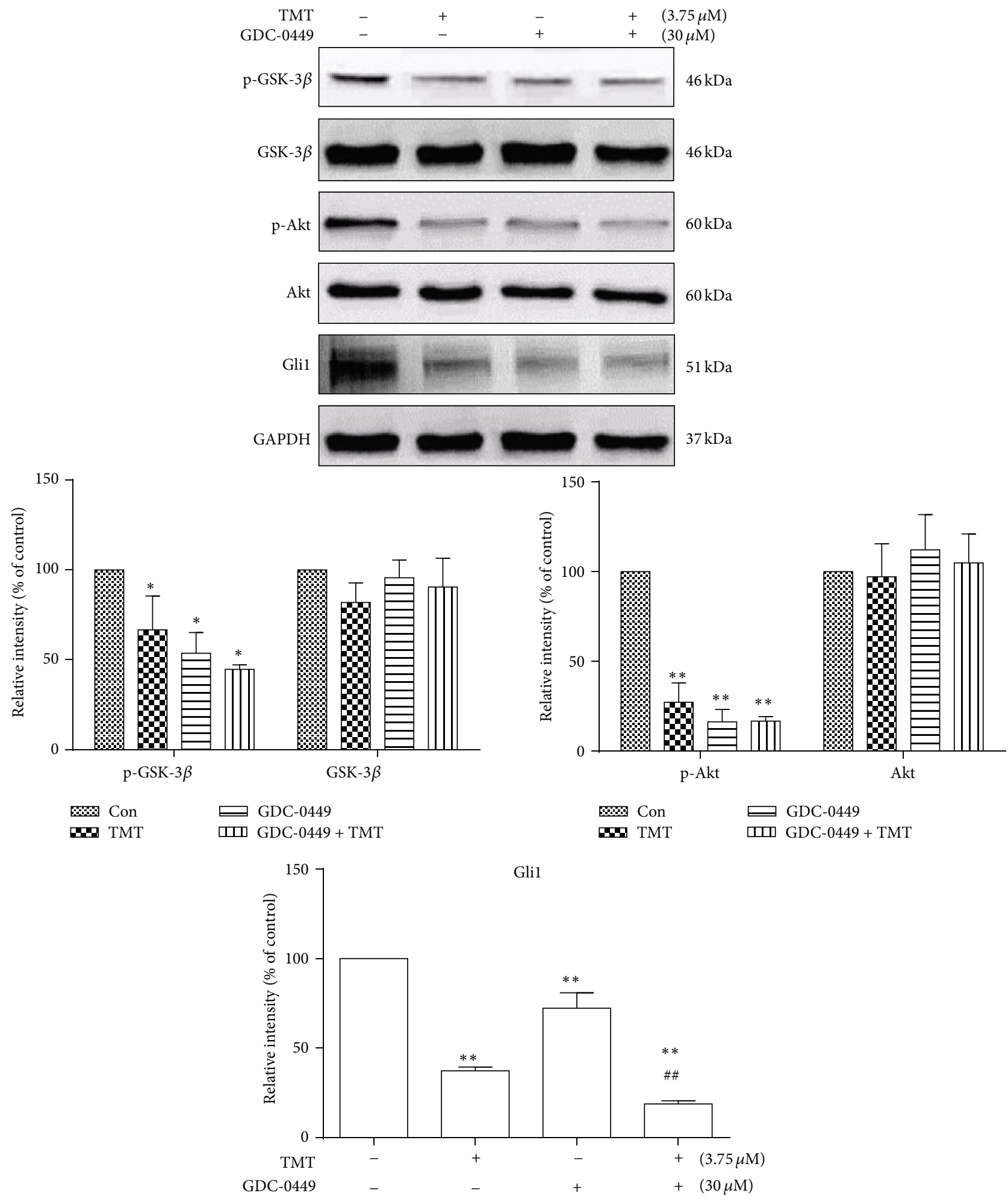

(b)

FIGURE 8: Effects of different antagonists on Shh and PI3K/Akt signaling pathways. Cells were pretreated with or without different inhibitors at different time points in the following concentrations: LY2940002, $10 \mu \mathrm{M}$; GDC-0449, $30 \mu \mathrm{M}$, before TMT treatment. After incubation with $3.75 \mu \mathrm{M}$ TMT for another $24 \mathrm{~h}$, the expression levels of proteins were determined through Western blot analysis. The mean protein expression of control group is designated as 1 in the graph. Each bar represents mean $\pm \mathrm{SD}(n=3) .{ }^{*} P<0.05,{ }^{* *} P<0.01$ compared with the control group; ${ }^{\#} P<0.05,{ }^{\# \#} P<0.01$ compared with the TMT-treated group. 
Shh pathway could downregulate phosphorylated GSK-3 $\beta$ by reducing Glil expression to affect Akt phosphorylation. We thereby consider that an interaction between Shh and PI3K/Akt pathways through modulating GSK-3 $\beta$ expression may be involved in TMT-induced apoptosis in N2a cells. Specifically speaking, PI3K/Akt pathway could influence GSK-3 $\beta$ expression to regulate Shh signaling, whereas Shh signaling was able to regulate Glil and GSK- $3 \beta$ expression to mediate PI3K/Akt signaling.

LBP is widely used in the manufacture of health care products to improve immunity, neuronal protection, and antiaging $[14,18,34]$. In a variety of methods that were used to relieve nerve damage caused by TMT, LBP could be a good choice because of its advantages of being cheap and available. Our preliminary experiment showed that a concentration range of $50 \sim 500 \mu \mathrm{g} / \mathrm{mL}$ LBP significantly improved cell viability, in which the concentration of LBP at $300 \mu \mathrm{g} / \mathrm{mL}$ played best effect on TMT-induced cytotoxicity in N2a cells $[14,18,34]$. Many studies have shown that LBP could scavenge free radicals and reduce lipid peroxidation [35]. LBP not only exhibits a protective effect on $\mathrm{A} \beta$ caused neurotoxicity, but also inhibits the formation of traumatic neuroma [36]. In this study, LBP significantly reduced oxidation-promoting factors levels, such as ROS and MDA, and antioxidant SOD levels, upregulated antiapoptotic genes Bcl-2, downregulated proapoptotic genes Bax, lowered caspase- 3 activity, and protected against neuronal apoptosis in TMT-treated N2a cells. In the aspect of mechanisms, the protective pathway PI3K/Akt signaling was activated after LBP treatment. The Shh signaling pathway downstream Glil gene expression also markedly increased compared with TMT treatment. The phosphorylated GSK- $3 \beta$ reduction by TMT was reversed by LBP addition. Thus, LBP could antagonize TMT-induced toxicity by exerting antioxidative effect and initiating Shh and PI3K/Akt signaling pathways in N2a cells. LBP can be proposed as a protective agent against TMT neurotoxicity in clinic.

\section{Conclusion}

In brief, TMT treatment induced neuronal apoptosis by causing oxidative stress, regulating apoptotic genes, and inhibiting Shh and PI3K/Akt signaling pathways. An interaction between Shh and PI3K/Akt signaling pathways is confirmed. LBP played a protective role in TMT-induced neurotoxicity by decreasing oxidative stress and activating Shh and PI3K/Akt signaling pathway. These findings suggest that Shh and PI3K/Akt signaling pathways may be potential therapeutic targets in the molecule mechanisms of TMTinduced nerve damage (Figure 9).

\section{Abbreviations}

TMT: Trimethyltin chloride

LBP: $\quad$ Lycium barbarum polysaccharides

Shh: Sonic Hedgehog

GSK-3 $\beta$ : Glycogen synthase kinase- $3 \beta$

N2a: Neuro-2a

ROS: $\quad$ Reactive oxygen species

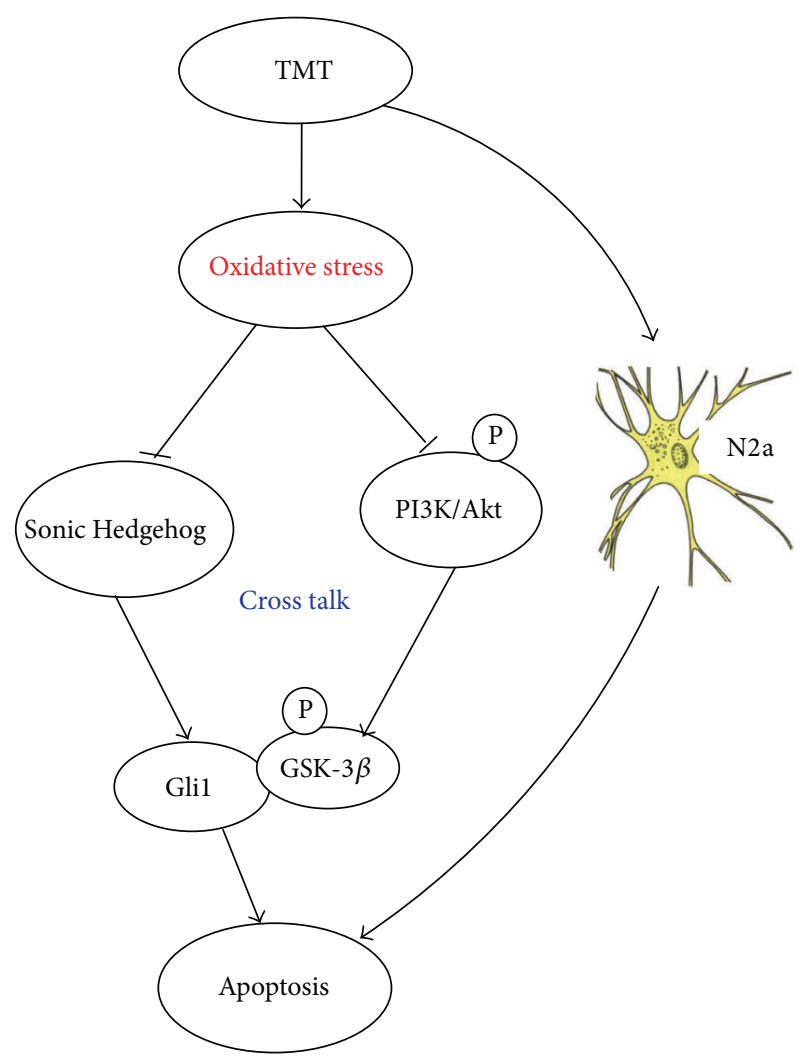

FIGURE 9: Mechanisms of TMT-induced apoptosis in N2a cells.

MDA: Malondialdehyde

SOD: $\quad$ Superoxide dismutase

PD: $\quad$ Parkinson's disease

AD: $\quad$ Alzheimer's disease

DMEM: Dulbecco's modified Eagle's medium

MTT: $\quad 3$-(4,5-Dimethylthiazol-2-yl)-2,5-diphenyltetrazolium bromide

DCFH-DA: 2,7-Dichlorofluorescein diacetate

FBS: $\quad$ Fetal bovine serum

DMSO: Dimethyl sulfoxide

TBA: Thiobarbituric acid.

\section{Competing Interests}

The authors declare that there are no competing interests in the present study.

\section{Acknowledgments}

The authors appreciate the contribution of all the members participating in this study. This work was financially supported by the National Natural Science Foundation of China (no. 814701512).

\section{References}

[1] J. Chen, C. Huang, L. Zheng et al., "Trimethyltin chloride (TMT) neurobehavioral toxicity in embryonic zebrafish," Neurotoxicology and Teratology, vol. 33, no. 6, pp. 721-726, 2011. 
[2] M. Fendt, T. Endres, C. A. Lowry, R. Apfelbach, and I. S. McGregor, "TMT-induced autonomic and behavioral changes and the neural basis of its processing," Neuroscience and Biobehavioral Reviews, vol. 29, no. 8, pp. 1145-1156, 2005.

[3] M. A. Philbert, M. L. Billingsley, and K. R. Reuhl, "Mechanisms of injury in the central nervous system," Toxicologic Pathology, vol. 28, no. 1, pp. 43-53, 2000.

[4] M. Shuto, K. Higuchi, C. Sugiyama et al., "Endogenous and exogenous glucocorticoids prevent trimethyltin from causing neuronal degeneration of the mouse brain in vivo: Involvement of oxidative stress pathways," Journal of Pharmacological Sciences, vol. 110, no. 4, pp. 424-436, 2009.

[5] V. Corvino, E. Marchese, F. Michetti, and M. C. Geloso, "Neuroprotective strategies in hippocampal neurodegeneration induced by the neurotoxicant trimethyltin," Neurochemical Research, vol. 38, no. 2, pp. 240-253, 2013.

[6] N. Kuramoto, K. Seko, C. Sugiyama, M. Shuto, and K. Ogita, "Trimethyltin initially activates the caspase 8/caspase 3 pathway for damaging the primary cultured cortical neurons derived from embryonic mice," Journal of Neuroscience Research, vol. 89, no. 4, pp. 552-561, 2011.

[7] C. A. McPherson, M. Aoyama, and G. J. Harry, "Interleukin (IL)-1 and IL-6 regulation of neural progenitor cell proliferation with hippocampal injury: differential regulatory pathways in the subgranular zone (SGZ) of the adolescent and mature mouse brain," Brain, Behavior, and Immunity, vol. 25, no. 5, pp. 850-862, 2011.

[8] Y. Qing, Y. Liang, Q. Du et al., "Apoptosis induced by Trimethyltin chloride in human neuroblastoma cells SY5Y is regulated by a balance and cross-talk between NF- $\kappa \mathrm{B}$ and MAPKs signaling pathways," Archives of Toxicology, vol. 87, no. 7, pp. 1273-1285, 2013.

[9] D. H. Oh, Y. C. Park, and S. H. Kim, "Increased glycogen synthase kinase- $3 \beta$ mRNA level in the hippocampus of patients with major depression: a study using the Stanley neuropathology consortium integrative database," Psychiatry Investigation, vol. 7, no. 3, pp. 202-207, 2010.

[10] F. Takahashi-Yanaga, "Activator or inhibitor? GSK-3 as a new drug target," Biochemical Pharmacology, vol. 86, no. 2, pp. 191199, 2013.

[11] C.-L. Wu, C.-S. Hwang, S.-D. Chen, J.-H. Yin, and D.-I. Yang, "Neuroprotective mechanisms of brain-derived neurotrophic factor against 3-nitropropionic acid toxicity: therapeutic implications for Huntington's disease," Annals of the New York Academy of Sciences, vol. 1201, pp. 8-12, 2010.

[12] R. L. Dai, S. Y. Zhu, Y. P. Xia et al., "Sonic hedgehog protects cortical neurons against oxidative stress," Neurochemical Research, vol. 36, no. 1, pp. 67-75, 2011.

[13] M. I. H. Bhuiyan, S. Y. Jung, H. J. Kim, Y. S. Lee, and C. Jin, "Major role of the PI3K/Akt pathway in ischemic tolerance induced by sublethal oxygen-glucose deprivation in cortical neurons in vitro," Archives of Pharmacal Research, vol. 34, no. 6, pp. 1023-1034, 2011.

[14] Y.-S. Ho, K.-F. So, and R. C.-C. Chang, "Anti-aging herbal medicine-how and why can they be used in aging-associated neurodegenerative diseases?" Ageing Research Reviews, vol. 9, no. 3, pp. 354-362, 2010.

[15] H.-Y. Li, Y.-W. Ruan, P. Wan-Foon Kau et al., "Effect of lycium barbarum (Wolfberry) on alleviating axonal degeneration after partial optic nerve transection," Cell Transplantation, vol. 24, no. 3, pp. 403-417, 2015.
[16] X. M. Li, Y. L. Ma, and X. J. Liu, "Effect of the Lycium barbarum polysaccharides on age-related oxidative stress in aged mice," Journal of Ethnopharmacology, vol. 111, no. 3, pp. 504-511, 2007.

[17] M.-S. Yu, S. K.-Y. Leung, S.-W. Lai et al., "Neuroprotective effects of anti-aging oriental medicine Lycium barbarum against $\beta$-amyloid peptide neurotoxicity," Experimental Gerontology, vol. 40, no. 8-9, pp. 716-727, 2005.

[18] Y.-S. Ho, M.-S. Yu, S.-Y. Yik, K.-F. So, W.-H. Yuen, and R. C.-C. Chang, "Polysaccharides from wolfberry antagonizes glutamate excitotoxicity in rat cortical neurons," Cellular and Molecular Neurobiology, vol. 29, no. 8, pp. 1233-1244, 2009.

[19] K. T. LePage, R. W. Dickey, W. H. Gerwick, E. L. Jester, and T. F. Murray, "On the use of neuro-2a neuroblastoma cells versus intact neurons in primary culture for neurotoxicity studies," Critical Reviews in Neurobiology, vol. 17, no. 1, pp. 27-50, 2005.

[20] M. Qu, Z. Zhou, C. Chen et al., "Lycopene protects against trimethyltin-induced neurotoxicity in primary cultured rat hippocampal neurons by inhibiting the mitochondrial apoptotic pathway," Neurochemistry International, vol. 59, no. 8, pp. 10951103, 2011.

[21] B. Viviani, E. Corsini, M. Pesenti, C. L. Galli, and M. Marinovich, "Trimethyltin-activated cyclooxygenase stimulates tumor necrosis factor- $\alpha$ release from glial cells through reactive oxygen species," Toxicology and Applied Pharmacology, vol. 172, no. 2, pp. 93-97, 2001.

[22] P. Casalbore, I. Barone, A. Felsani et al., "Neural stem cells modified to express BDNF antagonize trimethyltin-induced neurotoxicity through PI3K/Akt and MAP kinase pathways," Journal of Cellular Physiology, vol. 224, no. 3, pp. 710-721, 2010.

[23] A. M. Brennan-Minnella, Y. Shen, J. El-Benna, and R. A. Swanson, "Phosphoinositide 3-kinase couples NMDA receptors to superoxide release in excitotoxic neuronal death," Cell Death and Disease, vol. 4, no. 5, article e624, 2013.

[24] T. Dal-Cim, S. Molz, J. Egea et al., "Guanosine protects human neuroblastoma SH-SY5Y cells against mitochondrial oxidative stress by inducing heme oxigenase- 1 via PI3K/Akt/GSK-3 $\beta$ pathway," Neurochemistry International, vol. 61, no. 3, pp. 397404, 2012.

[25] R. N. Wine, C. A. McPherson, and G. J. Harry, "IGF-1 and pAKT signaling promote hippocampal CA1 neuronal survival following injury to dentate granule cells," Neurotoxicity Research, vol. 16, no. 3, pp. 280-292, 2009.

[26] O. Bragina, S. Sergejeva, M. Serg et al., "Smoothened agonist augments proliferation and survival of neural cells," Neuroscience Letters, vol. 482, no. 2, pp. 81-85, 2010.

[27] L. Chen, C. Huang, C. Hu, K. Yu, L. Yang, and B. Zhou, "Acute exposure to DE-71: effects on locomotor behavior and developmental neurotoxicity in zebrafish larvae," Environmental Toxicology and Chemistry, vol. 31, no. 10, pp. 2338-2344, 2012.

[28] A. Gulino, L. Di Marcotullio, E. Ferretti, E. De Smaele, and I. Screpanti, "Hedgehog signaling pathway in neural development and disease," Psychoneuroendocrinology, vol. 32, supplement 1, pp. S52-S56, 2007.

[29] K. Subramanian, S. S. Mohideen, A. Suzumura et al., "Exposure to 1-bromopropane induces microglial changes and oxidative stress in the rat cerebellum," Toxicology, vol. 302, no. 1, pp. 18-24, 2012.

[30] S. Z. Kaylani, J. Xu, R. K. Srivastava, L. Kopelovich, J. G. Pressey, and M. Athar, "Rapamycin targeting mTOR and hedgehog signaling pathways blocks human rhabdomyosarcoma growth in xenograft murine model," Biochemical and Biophysical Research Communications, vol. 435, no. 4, pp. 557-561, 2013. 
[31] Z. Ke, S. Caiping, Z. Qing, and W. Xiaojing, "Sonic hedgehogGlil signals promote epithelial-mesenchymal transition in ovarian cancer by mediating PI3K/AKT pathway," Medical Oncology, vol. 32, no. 1, article 368, 2015.

[32] L. Wei and Z. Xu, "Cross-signaling among phosphinositide-3 kinase, mitogenactivated protein kinase and sonic hedgehog pathways exists in esophageal cancer," International Journal of Cancer, vol. 129, no. 2, pp. 275-284, 2011.

[33] Y. A. Yoo, M. H. Kang, H. J. Lee et al., "Sonic hedgehog pathway promotes metastasis and lymphangiogenesis via activation of Akt, EMT, and MMP-9 pathway in gastric cancer," Cancer Research, vol. 71, no. 22, pp. 7061-7070, 2011.

[34] K. Chiu, Y. Zhou, S.-C. Yeung et al., "Up-regulation of crystallins is involved in the neuroprotective effect of wolfberry on survival of retinal ganglion cells in rat ocular hypertension model," Journal of Cellular Biochemistry, vol. 110, no. 2, pp. 311-320, 2010.

[35] S.-Y. Li, D. Yang, C.-M. Yeung et al., "Lycium barbarum polysaccharides reduce neuronal damage, blood-retinal barrier disruption and oxidative stress in retinal ischemia/reperfusion injury," PLoS ONE, vol. 6, no. 1, Article ID e16380, 2011.

[36] X.-S. Mi, Q. Feng, A. C. Y. Lo et al., "Protection of retinal ganglion cells and retinal vasculature by Lycium barbarum polysaccharides in a mouse model of acute ocular hypertension," PLoS ONE, vol. 7, no. 10, Article ID e45469, 2012. 


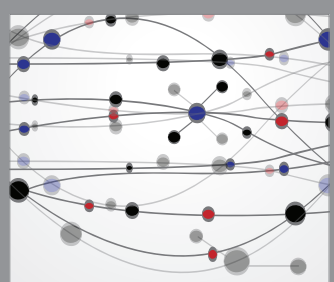

The Scientific World Journal
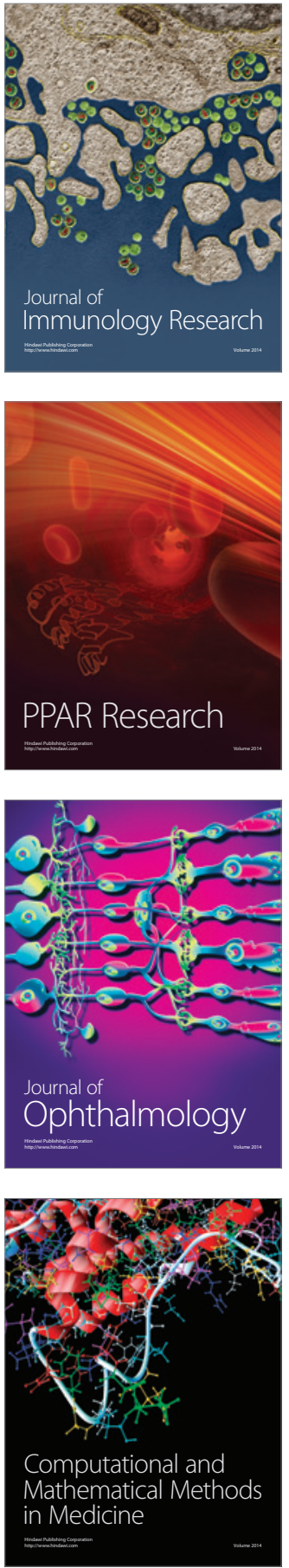

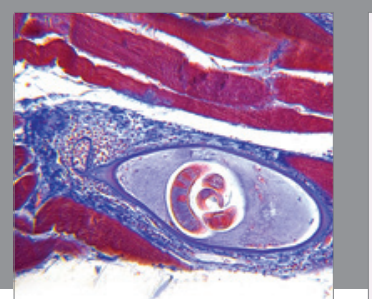

Gastroenterology Research and Practice

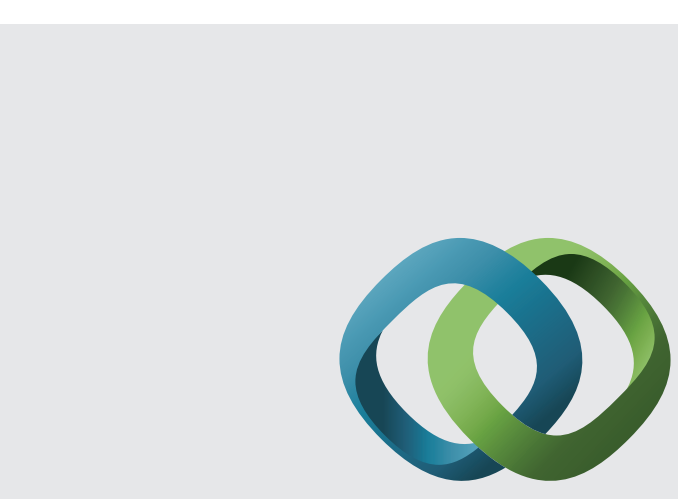

\section{Hindawi}

Submit your manuscripts at

http://www.hindawi.com
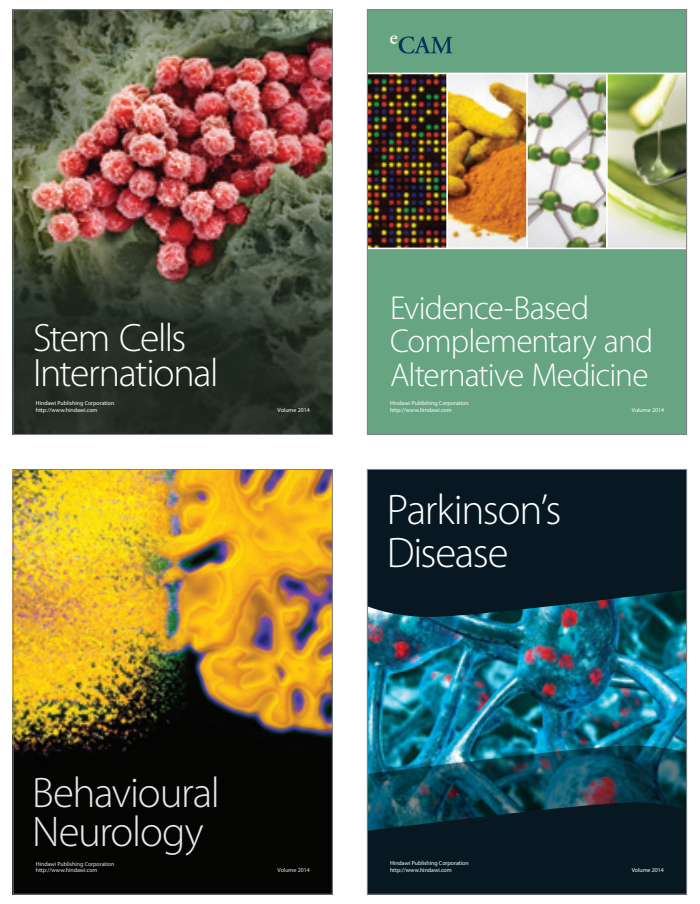
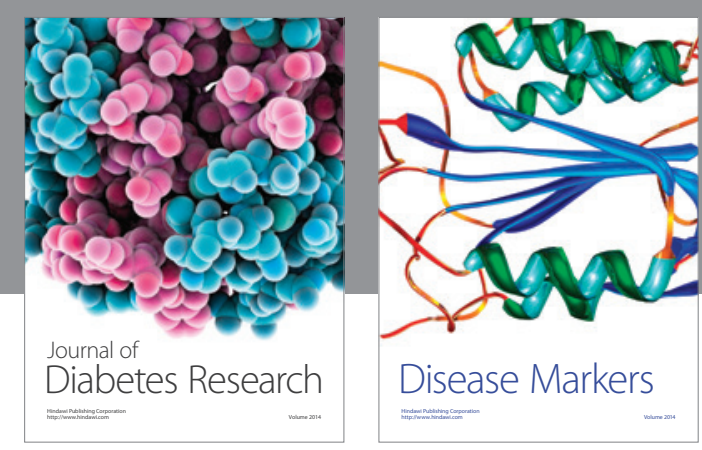

Disease Markers
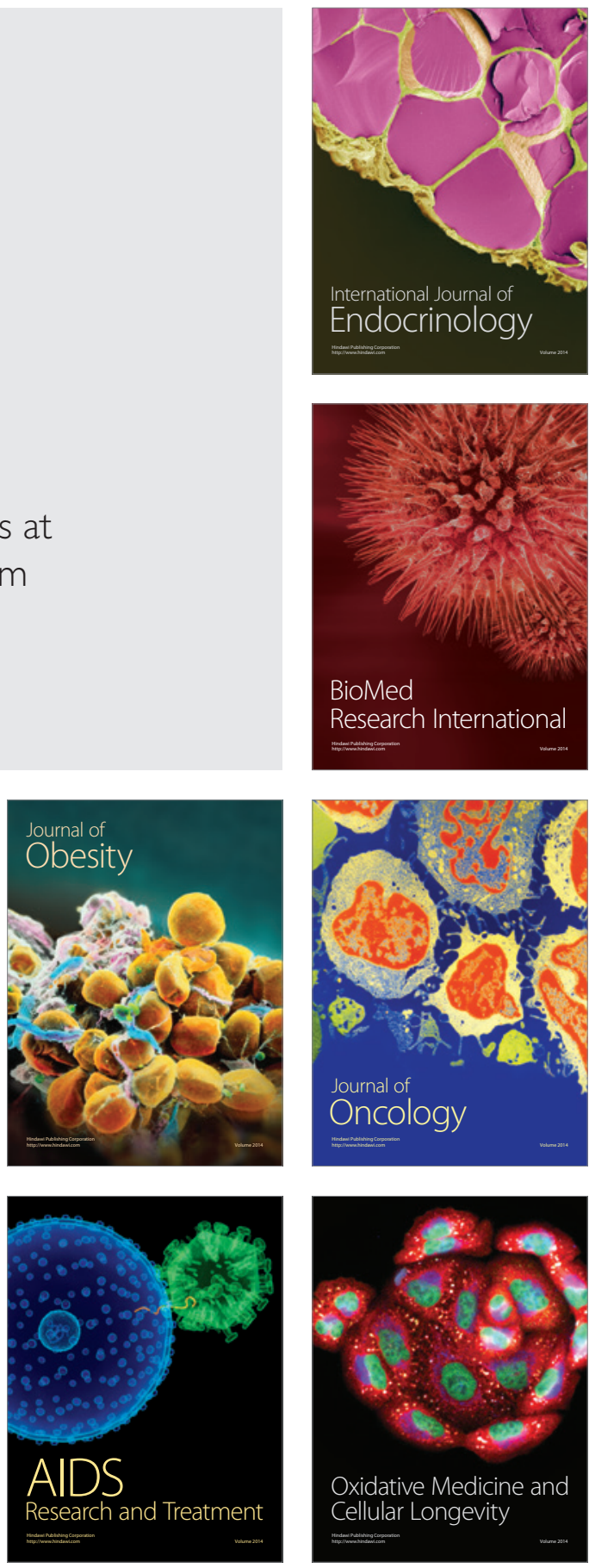